\title{
Ionization, luminosity, and heating of the upper atmosphere of Mars
}

\section{Citation}

Fox, J. L., and A. Dalgarno. 1979. “Ionization, Luminosity, and Heating of the Upper Atmosphere of Mars." Journal of Geophysical Research 84 (A12): 7315. doi:10.1029/ja084ia12p07315.

\section{Published Version}

doi:10.1029/JA084iA12p07315

\section{Permanent link}

http://nrs.harvard.edu/urn-3:HUL.InstRepos:30410807

\section{Terms of Use}

This article was downloaded from Harvard University's DASH repository, and is made available under the terms and conditions applicable to Other Posted Material, as set forth at http:// nrs.harvard.edu/urn-3:HUL.InstRepos:dash.current.terms-of-use\#LAA

\section{Share Your Story}

The Harvard community has made this article openly available.

Please share how this access benefits you. Submit a story.

\section{Accessibility}




\title{
Ionization, Luminosity, and Heating of the Upper Atmosphere of Mars
}

\author{
J. L. Fox' AND A. Dalgarno
}

Harvard-Smithsonian Center for Astrophysics, Cambridge, Massachusetts 02138

\begin{abstract}
A model based upon Viking data is constructed of the Martian atmosphere, and a comprehensive quantitative discussion is given of the measurements of the ultraviolet dayglow. A detailed assessment is made of the heating of the neutral and ionized components of the atmosphere arising from the absorption of ultraviolet solar radiation.
\end{abstract}

\section{INTRODUCTION}

The experiments performed during the entry of the Viking landers 1 and 2 provided many new data on the structure and composition of the upper atmosphere of Mars. The neutral mass spectrometric measurements confirmed that $\mathrm{CO}_{2}$ is the major atmospheric constituent and demonstrated the presence of small quantities of $\mathrm{N}_{2}, \mathrm{Ar}, \mathrm{O}_{2}, \mathrm{CO}$, and $\mathrm{NO}$ [Nier and McElroy, 1977]. The retarding potential analyzer experiment returned data on the electron and ion densities and on the ion temperatures. The electron density attained a peak value of about $10^{5} \mathrm{~cm}^{-3}$ at an altitude of $130 \mathrm{~km}$, and the topside scale height was about $29 \mathrm{~km}$. Over the altitude range from 120 to $200 \mathrm{~km}$ sampled during entry, $\mathrm{O}_{2}{ }^{+}$was the major ionic constituent, and the ratio of the concentrations of $\mathrm{O}_{2}{ }^{+}$to $\mathrm{CO}_{2}{ }^{+}$at the ionospheric peak was 9:1 [Hanson et al., 1977].

Taken in conjunction with the earlier results from the Mariner missions, the detailed knowledge of the upper atmosphere of Mars gained from the Viking experiments provides a useful test of our understanding of the processes that occur in an atmosphere dominated by $\mathrm{CO}_{2}$.

In this paper we construct a model of the upper atmosphere of Mars based upon Viking 1 data, and we use measured chemical reaction rates and measured photoabsorption and electron impact cross sections to calculate the electron and ion density profiles.

Comparison with the measured profiles leads to a determination of the abundance of atomic oxygen. We also present a quantitative description of the processes giving rise to the Martian dayglow and compare the calculated dayglow intensities with those measured on the Mariner 6, 7, and 9 spacecraft [Barth et al., 1969, 1971, 1972; Stewart et al., 1972; Stewart, 1972].

\section{The Model ATMOSPHERE}

Our model atmosphere was designed to reproduce the measured $\mathrm{CO}_{2}$ densities at and above the ion peak. The turbopause was chosen to be at an altitude of $120 \mathrm{~km}$, and above $120 \mathrm{~km}$ the atmosphere was represented by a distribution in diffusive equilibrium. The kinetic temperature is not important in our discussion except as it affects the density profiles, and we made no attempt to reproduce the neutral particle temperature profile derived from Viking 1 density data

\footnotetext{
'Also at the Department of Chemistry, Harvard University, Cambridge, Massachussetts 02138. Now at the Division of Applied Sciences, Harvard University, Cambridge, Massachusetts 02138.

Copyright $(\mathcal{1} 1979$ by the American Geophysical Union.
}

[McElroy et al., 1976]. A thermospheric temperature profile of the form

$$
T_{n}=T_{\infty}+\left(T_{0}-T_{\infty}\right) \exp \left[\left(z-z_{0}\right) / s\right]
$$

where $s$ is a disposable parameter, $T_{0}=130 \mathrm{~K}$ at $z_{0}=100 \mathrm{~km}$, and the exospheric temperature $T_{\infty}=225^{\circ}$, closely reproduces the measured $\mathrm{CO}_{2}$ density distribution throughout the region where most of the dayglow originates. The adopted temperature profile is shown in Figure 1.

Mixing ratios of the minor constituents at the turbopause were chosen to achieve a satisfactory fit to the Viking profiles [Nier and McElroy, 1976]. The adopted mixing ratios are 2.5\% for $\mathrm{N}_{2}, 1.5 \%$ for $\mathrm{Ar}, 0.12 \%$ for $\mathrm{O}_{2}, 0.42 \%$ for $\mathrm{CO}$, and $0.007 \%$ for NO. The profiles are shown in Figure 2 together with measured densities.

The electron temperatures $T_{e}$ are not known. We adopted an altitude profile, shown in Figure 1, which is consistent with that resulting from local photoelectron heating with unimpeded thermal conduction. The adopted profile leads to an $\mathrm{O}_{2}{ }^{+}$profile that is in agreement with the measured concentrations. The consequences of higher electron temperatures will be discussed later.

The ion temperatures $T_{i}$ were measured on Viking 1 [Hanson et al., 1977], and a smoothed version of them is reproduced in Figure 1.

\section{Atomic and Molecular Data}

The primary photoelectrons are produced by ionization of the neutral atmospheric constituents by solar photons. In computing the energy of the ejected electrons, ionization to various electronic states of the ions was considered, but all molecular species were assumed to be in their vibrational ground states. Photoabsorption and photo-ionization of $\mathrm{CO}_{2}$, $\mathrm{Ar}, \mathrm{N}_{2}$, and $\mathrm{O}$ are included in the calculation.

The electrons created were assigned to energy intervals in a grid of 125 bins, each $1 \mathrm{eV}$ wide. Photoelectrons with energies greater than $125 \mathrm{eV}$ were converted into an electron of energy $125 \mathrm{eV}$ and an extra electron with the remainder of the energy. The approximation overestimates the number of excitations relative to ionizations, since the energy loss per ion pair decreases with increasing incident electron energy, and it particularly underestimates processes with high threshold energies. The effects are negligible except possibly near altitudes of $100 \mathrm{~km}$, where high-energy photons are responsible for the bulk of the ionizations.

The photoabsorption cross sections for $\mathrm{CO}_{2}$ for the wavelength range $580-1670 \AA$ were taken from Nakata et al. [1965]. For the interval $185-580 \AA$ we used the measurements of J. A. R. Samson and G. N. Haddad (unpublished data 


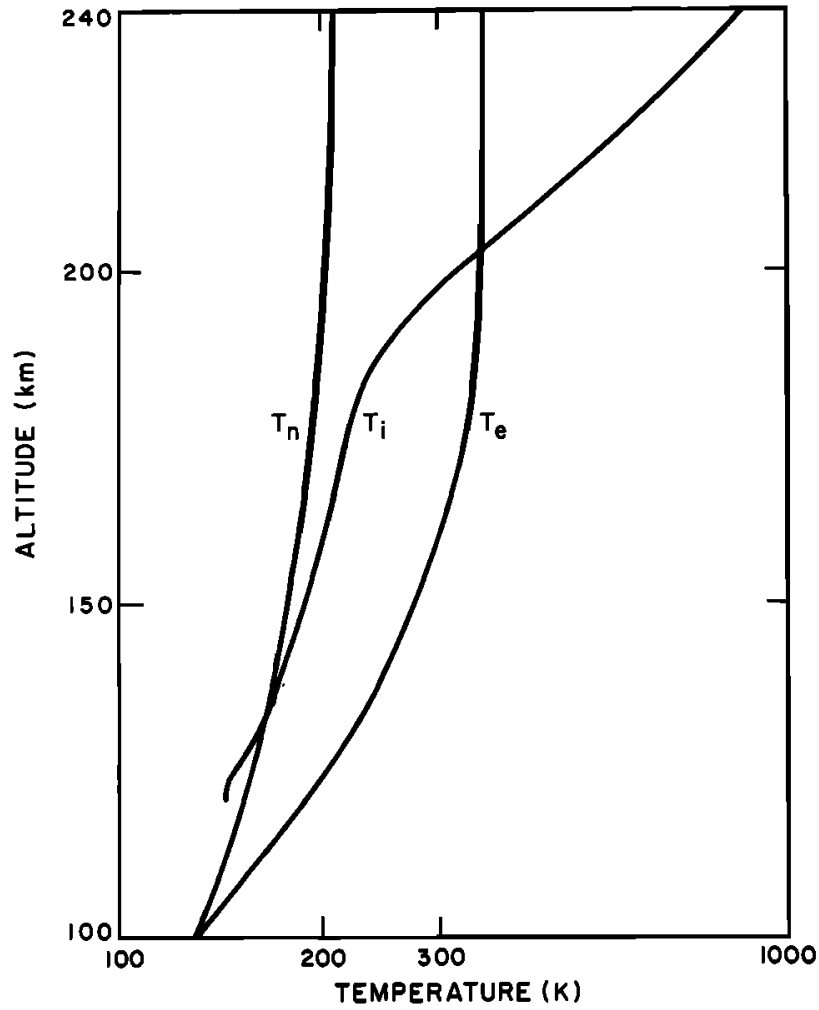

Fig. 1. The adopted temperature profiles. The ion temperatures are a smoothed version of those measured by Viking 1 . The electron and neutral temperatures were constructed to roughly reproduce measured neutral and ion concentrations.

quoted by Samson and Gardner [1973b]), and from 1700 to $2000 \AA$ we used the measurements of Ogawa [1971]. Below $185 \AA$ the cross sections were estimated by adding the cross sections for atomic carbon to twice the atomic oxygen cross sections calculated by McGuire [1968]. The cross sections estimated in this way agree well with the measured cross sections at short wavelengths.

The branching ratios for ionization to excited states of $\mathrm{CO}_{2}{ }^{+}$were obtained by combining the branching ratio for populating the $A^{2} \Pi_{u}$ and $B^{2} \Sigma_{u}{ }^{+}$states for the wavelength range 304-620 $\AA$ measured by Gustaffson et al. [1978] with the ratio of the $A^{2} \Pi_{u}$ and $B^{2} \Sigma_{u}{ }^{+}$population efficiencies measured by Samson and Gardner [1973a]. Below $304 \AA$ the relative proportions of the $X, A$, and $B$ states of $\mathrm{CO}_{2}{ }^{+}$were assumed to remain constant, but the fragment/ion ratio was interpolated between 14 and $304 \AA$ to yield the value measured by van Brunt et al. [1972] at $44 \AA$.

The $\mathrm{C}^{2} \mathrm{\Sigma}_{\mathrm{g}}^{+}$state of $\mathrm{CO}_{2}^{+}$is completely predissociated [Eland, 1972; Lee and Judge, 1972; Parr and Taylor, 1974; Eland and Berkowitz, 1977]. Only dissociation to $\mathrm{O}^{+}+\mathrm{CO}$ is possible from the ground vibrational level of the $C$ state, but dissociation to $\mathrm{CO}^{+}+\mathrm{O}$ is possible from excited vibrational levels. We have assumed the $C$ state to be $80 \%$ predissociated into $\mathrm{O}^{+}+\mathrm{CO}$ and $20 \%$ into $\mathrm{CO}^{+}+\mathrm{O}$. This $\mathrm{O}^{+} / \mathrm{CO}^{+}$ratio is an average of the ratios reported by Dibeler and Walker [1967], McCulloh [1973], and Eland and Berkowitz [1977].

The argon photoabsorption cross sections were taken from Cairns and Samson [1965] and Samson [1966]. The nitrogen total absorption cross sections for the region from 180 to 650 $\AA$ were taken from Lee et al. [1973]. Below $180 \AA$ and between 650 and $734 \AA$ the data were extrapolated to the cross sections measured by Huffman [1969] and between 734 and $986 \AA$ to the cross sections obtained from the tabulated oscillator strengths of Carter [1972]. Branching ratios for ionization from 668 to $796 \AA$ were taken from Cook and Metzger [1964]. Shortward of $668 \AA$ the ionization yield was assumed to be unity. The dissociative ionization threshold for nitrogen is 509 $\AA$. The branching ratios for dissociative ionization were taken from Wight et al. [1976] and Fryar and Browning [1973], and

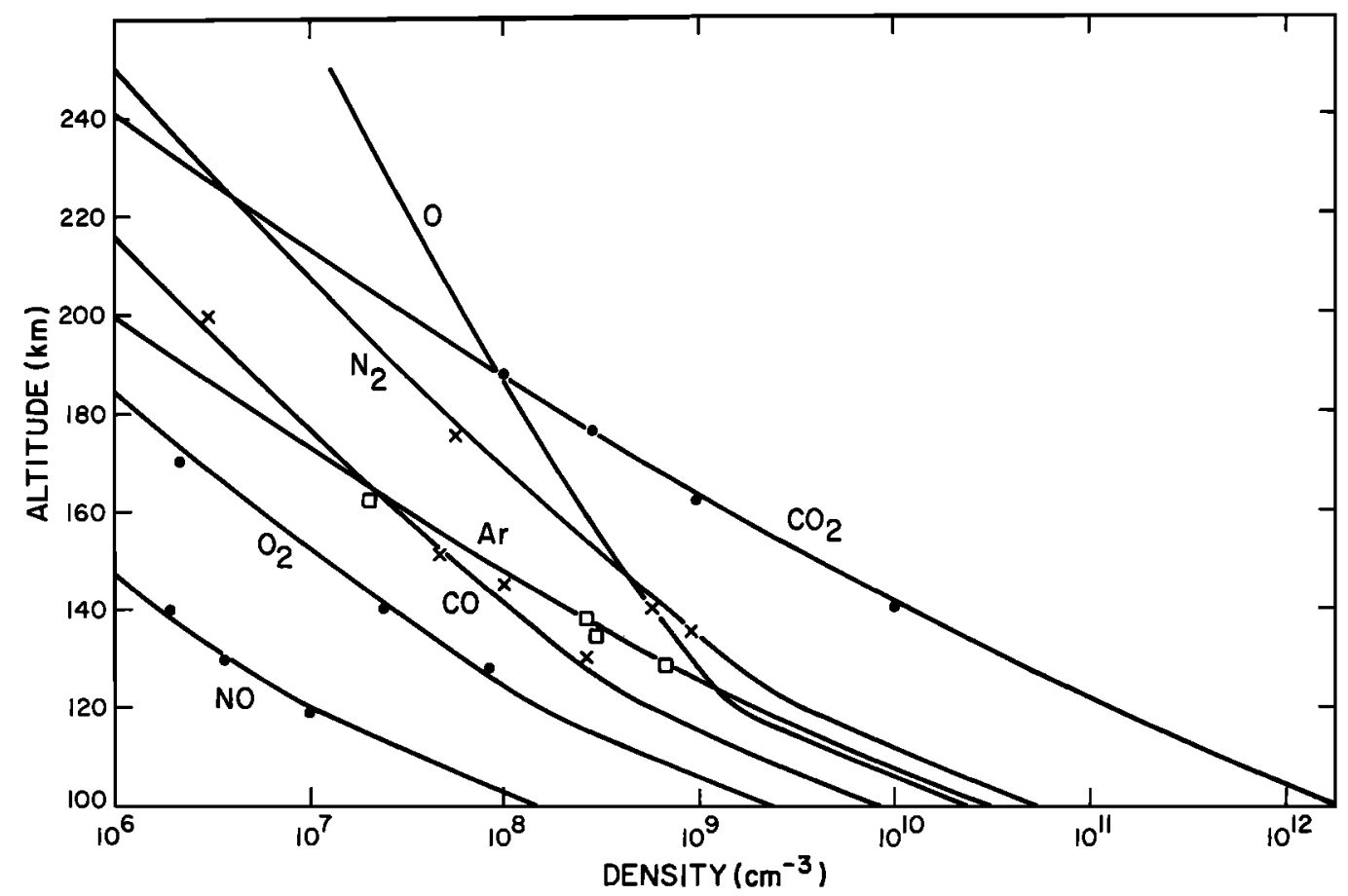

Fig. 2. Altitude profiles of the major neutral species. Our profiles are compared to some of the densities measured by Viking 1 . The $\mathrm{CO}_{2}, \mathrm{O}_{2}$, and $\mathrm{NO}$ measurements are represented by solid circles, the $\mathrm{CO}$ and $\mathrm{N}_{2}$ densities by crosses, and the Ar densities by open squares. 


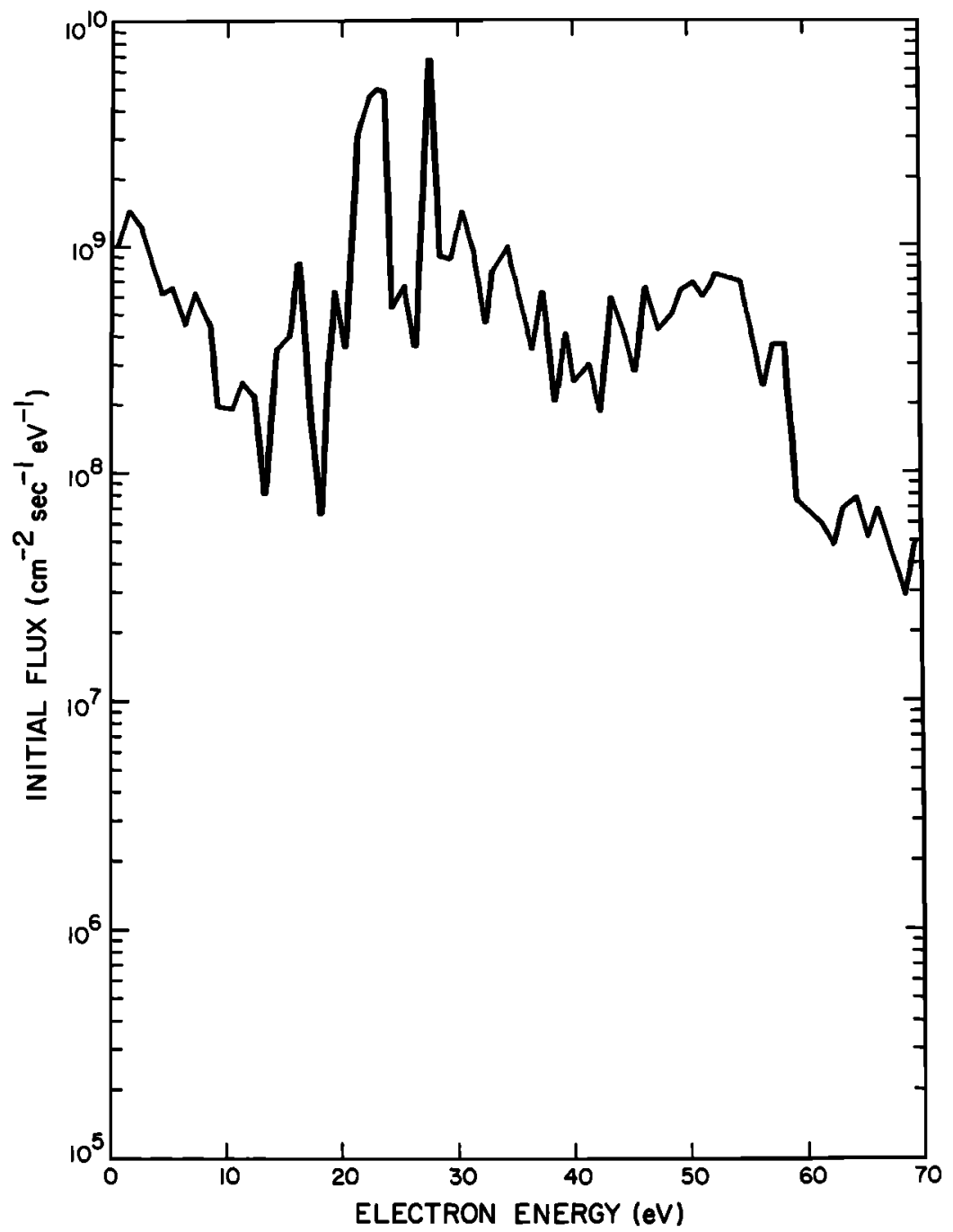

Fig. 3. Primary photoelectron flux at $130 \mathrm{~km}$.

the branching ratios for excited states of $\mathrm{N}_{2}{ }^{+}$were taken from Samson et al. [1977].

The cross sections for ionization of atomic oxygen to the $\mathrm{O}^{+}\left({ }^{4} S^{0}\right), \mathrm{O}^{+}\left({ }^{2} D^{0}\right)$, and $\mathrm{O}^{+}\left({ }^{2} P^{0}\right)$ states were taken from Henry [1967], which were renormalized to the total ionization cross sections of Taylor and Burke [1976]. The cross sections for production of the $\mathrm{O}^{+}\left({ }^{4} \mathrm{P}^{e}\right)$ and $\mathrm{O}^{+}\left({ }^{2} \mathrm{P}^{\mathrm{C}}\right)$ states were obtained from the calculations of Dalgarno et al. [1964], modified by Henry [1967].

Electron impact cross sections for $\mathrm{CO}_{2}$ have been compiled by Fox and Dalgarno [1979], for Ar by Fox et al. [1977b], and for atomic oxygen by Dalgarno and Lejeune [1971]. For nitrogen the cross sections have been listed by G. A. Victor (unpublished compilation, 1978), whose tabulation is based on the excitation cross sections of Cartwright et al. [1977] and Chutjian et al. [1977], the dissociation cross sections of Winters [1966] and Niehaus [1967], and the ionization cross section of Rapp and Englander-Golden [1965]. The dissociation cross sections measured by Winters [1966] and by Niehaus [1967] have been confirmed by Zipf and McLaughlin [1978].

The solar fluxes were those of the $\mathbf{R} 74113$ reference spectrum of Hinteregger [1976], scaled in absolute intensity for the position of Mars at the time of the entry of Viking 1 . The results we report correspond to a solar zenith angle of $45^{\circ}$.

\section{Photoelectron FluXes}

The steady state photoelectron fluxes were calculated following procedures described by Dalgarno and Lejeune [1971] and Cravens et al. [1975]. The primary and steady state fluxes at an altitude of $130 \mathrm{~km}$ are shown in Figures 3 and 4. They are similar to those calculated by Mantas and Hanson [1979].

The primary spectrum is highly structured. The largest peaks are a result of ionization by intense solar line emissions. The sharp peak at $27 \mathrm{eV}$ is due to ionization of $\mathrm{CO}_{2}$ to the ground state of $\mathrm{CO}_{2}^{+}$by absorption of the solar $\mathrm{He}$ II line at $304 \AA$, and the broader peak between 21 and $24 \mathrm{eV}$ results from absorption of the $304-\AA$ line, leading to the $A^{2} \Pi_{u}$ and $B^{2} \Sigma_{u}{ }^{+}$states of $\mathrm{CO}_{2}{ }^{+}$and to dissociative ionization. Ionization of $\mathrm{CO}_{2}$ by several solar lines between 764 and $790 \AA$ is responsible for the low-energy peak at $2-3 \mathrm{eV}$, and the strong solar line at $171 \AA$ is responsible for the peak at $58 \mathrm{eV}$. The solar flux and the ionization cross sections decrease rapidly at shorter wavelengths, and the primary photoelectron energy spectrum falls off by an order of magnitude.

The same peaks persist in the steady state photoelectron fluxes, shown in Figure 4, although the spectrum is smoothed by the electron energy losses. There is a prominent dip near $3 \mathrm{eV}$ caused by vibrational excitations of $\mathrm{CO}_{2}$, for which the cross section is large and narrowly peaked near $3.5 \mathrm{eV}$. 


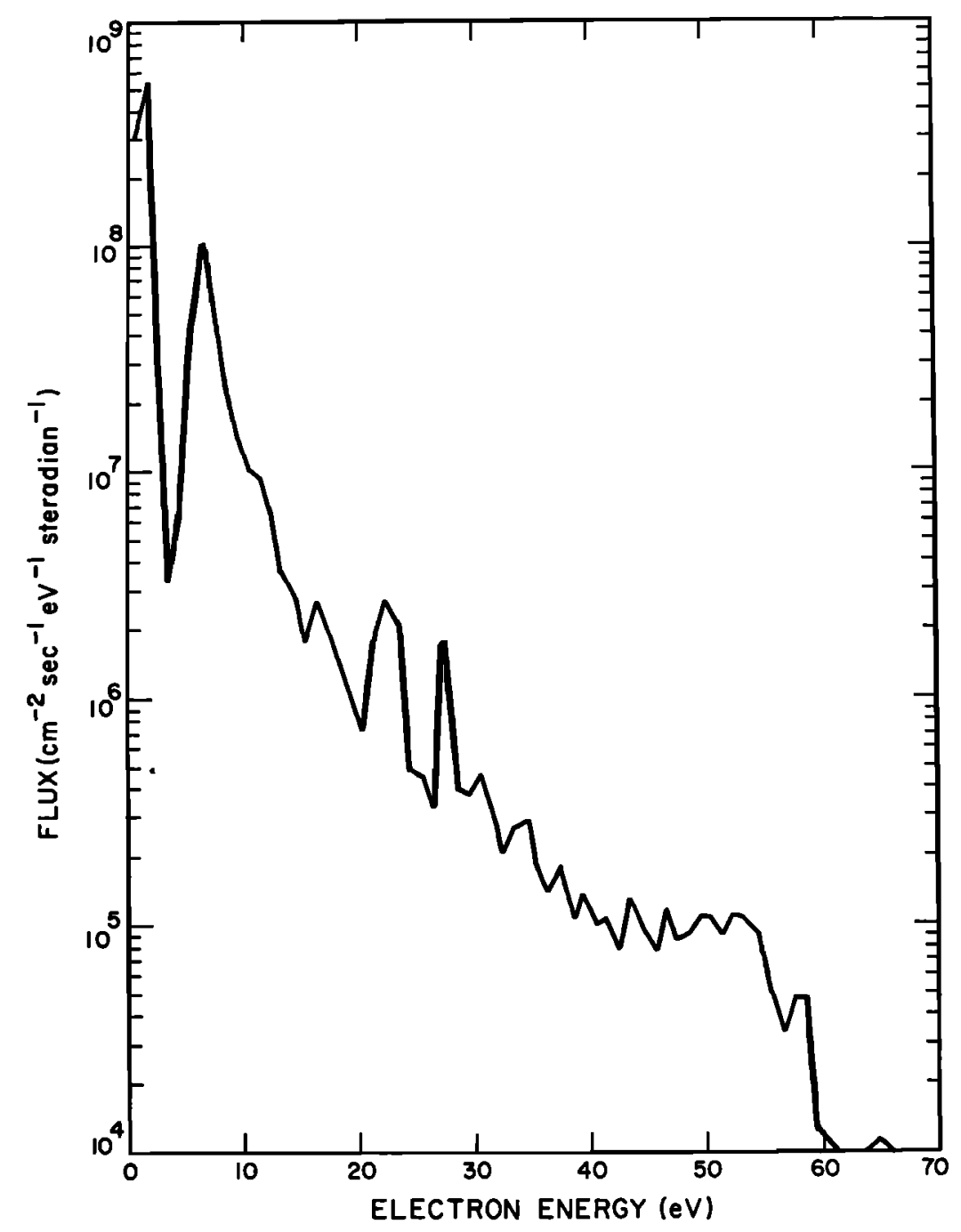

Fig. 4. Steady state photoelectron flux at $130 \mathrm{~km}$.

TABLE 1. Integrated Ion Production Rates

\begin{tabular}{|c|c|c|c|}
\hline Species & $\begin{array}{l}\text { Photo- } \\
\text { ionization }\end{array}$ & $\begin{array}{c}\text { Electron } \\
\text { Impact } \\
\text { Ionization }\end{array}$ & Total \\
\hline $\begin{array}{l}\mathrm{CO}_{2}^{+} \\
\left(X^{2} \Pi_{g}\right) \\
\left(A^{2} \Pi_{u}\right) \\
\left(B^{2} \Sigma_{u}^{+}\right) \\
\mathrm{C}^{+} \\
\mathrm{CO}^{+} \\
\mathrm{O}^{+} \\
\mathrm{Ar}^{+} \\
\mathrm{N}_{2}^{+} \\
\quad\left(X^{2} \Sigma_{\mathrm{g}}{ }^{+}\right) \\
\left(A^{2} \Pi_{u}\right) \\
\left(B^{2} \Sigma_{u}^{+}\right) \\
\mathrm{N}^{+} \\
\mathrm{O}^{+} \\
\left({ }^{4} S\right) \\
\left({ }^{2} D\right) \\
\left({ }^{2} P\right) \\
\left({ }^{4} P^{C}\right) \\
\left({ }^{2} P^{e}\right)\end{array}$ & $\begin{array}{r}3362 \\
1415 \\
1548 \\
57 \\
212 \\
694 \\
52 \\
184 \\
67 \\
83 \\
17 \\
31 \\
192 \\
73 \\
64 \\
39 \\
11 \\
6\end{array}$ & $\begin{array}{r}2219 \\
397 \\
237 \\
52 \\
103 \\
87 \\
58 \\
75 \\
59 \\
12 \\
4 \\
11 \\
105 \\
36 \\
45 \\
24 \\
\cdots \\
\ldots\end{array}$ & $\begin{array}{r}5581 \\
1812 \\
1785 \\
109 \\
315 \\
781 \\
110 \\
259 \\
126 \\
95 \\
21 \\
42 \\
297 \\
109 \\
109 \\
63 \\
11 \\
6\end{array}$ \\
\hline
\end{tabular}

Values are given in units of $10^{6} \mathrm{~cm}^{-2} \mathrm{~s}^{-1}$.

\section{ION AND Electron Concentrations}

The total production rates of the major ions resulting from photo-ionization and from photoelectron impact ionization are presented in Table 1 . The subsequent chemical reactions and their rate coefficients are listed in Table 2 . The major ion produced is $\mathrm{CO}_{2}^{+}$, but it is quickly removed by the reactions

$$
\begin{aligned}
& \mathrm{CO}_{2}^{+}+\mathrm{O} \rightarrow \mathrm{CO}+\mathrm{O}_{2}^{+} \\
& \mathrm{CO}_{2}^{+}+\mathrm{O} \rightarrow \mathrm{O}^{+}+\mathrm{CO}_{2} \\
& \mathrm{O}^{+}+\mathrm{CO}_{2} \rightarrow \mathrm{CO}+\mathrm{O}_{2}^{+}
\end{aligned}
$$

leading to $\mathrm{O}_{2}^{+}$, which is the major ion over all the altitudes considered.

The concentration of atomic oxygen was not measured by the Viking mass spectrometers, but it can be inferred from the measurements of $\mathrm{CO}_{2}{ }^{+}$concentrations. Thus to a close approximation,

$$
n\left(\mathrm{CO}_{2}^{+}\right)=\frac{P\left(\mathrm{CO}_{2}^{+}\right)}{\left(k_{1}+k_{2}\right) n(\mathrm{O})+k_{5} n(e)}
$$


TABLE 2. Chemical Reactions in the Martian lonosphere

\begin{tabular}{|c|c|c|c|c|}
\hline $\begin{array}{l}\text { Reaction } \\
\text { No. }\end{array}$ & Reaction & $\begin{array}{l}\text { Rate Coefficient, } \\
\qquad \mathrm{cm}^{3} \mathbf{s}^{-1}\end{array}$ & $\begin{array}{c}\text { Energy } \\
\text { Released, } \\
\text { eV }\end{array}$ & Reference \\
\hline $\begin{array}{l}\text { (R1) } \\
\text { (R2) } \\
\text { (R3) } \\
\text { (R4) } \\
\text { (R5) } \\
\text { (R6) } \\
\text { (R7) } \\
\text { (R8) } \\
\text { (R9) } \\
\text { (R10) } \\
\text { (R11) } \\
\text { (R12) } \\
\text { (R13) } \\
\text { (R14) } \\
\text { (R15) } \\
\text { (R16) } \\
\text { (R17) } \\
\text { (R18) }\end{array}$ & $\begin{array}{l}\mathrm{CO}_{2}^{+}+\mathrm{O} \rightarrow \mathrm{CO}+\mathrm{O}_{2}^{+} \\
\mathrm{CO}_{2}^{+}+\mathrm{O} \rightarrow \mathrm{CO}_{2}+\mathrm{O}^{+} \\
\mathrm{O}^{+}+\mathrm{CO}_{2} \rightarrow \mathrm{O}_{2}^{+}+\mathrm{CO} \\
\mathrm{O}_{2}^{+}+e \rightarrow \mathrm{O}+\mathrm{O} \\
\mathrm{CO}_{2}^{+}+e \rightarrow \mathrm{CO}+\mathrm{O} \\
\mathrm{CO}_{2}^{+}+\mathrm{NO} \rightarrow \mathrm{NO}^{+}+\mathrm{CO}_{2} \\
\mathrm{CO}_{2}^{+}+\mathrm{O}_{2} \rightarrow \mathrm{CO}_{2}+\mathrm{O}_{2}^{+} \\
\mathrm{N}_{2}^{+}+\mathrm{CO}_{2} \rightarrow \mathrm{N}_{2}+\mathrm{CO}_{2} \\
\left.\mathrm{~N}_{2}^{+}+\mathrm{O} \rightarrow \mathrm{NO}^{+}+\mathrm{N}^{2} D\right) \\
\left.\mathrm{N}_{2}^{+}+e \rightarrow \mathrm{N}+\mathrm{N}^{2} D\right) \\
\mathrm{N}_{2}^{+}+\mathrm{CO} \rightarrow \mathrm{N}_{2}+\mathrm{CO}^{+} \\
\mathrm{Ar}^{+}+\mathrm{CO}_{2} \rightarrow \mathrm{Ar}+\mathrm{CO}_{2}^{+} \\
\mathrm{Ar}^{+}+\mathrm{N}_{2} \rightarrow \mathrm{Ar}+\mathrm{N}_{2}^{+} \\
\mathrm{N}^{+}+\mathrm{CO}_{2} \rightarrow \mathrm{N}+\mathrm{CO}_{2}^{+} \\
\mathrm{NO}^{+}+e \rightarrow \mathrm{N}\left({ }^{2} D\right)+\mathrm{O}^{+} \\
\mathrm{O}_{2}^{+}+\mathrm{NO}^{+} \mathrm{NO}^{+}+\mathrm{O}_{2} \\
\mathrm{C}^{+}+\mathrm{CO}_{2} \rightarrow \mathrm{CO}^{+}+\mathrm{CO}^{+} \\
\mathrm{CO}^{+}+\mathrm{CO}_{2} \rightarrow \mathrm{CO}_{2}^{+}+\mathrm{CO}\end{array}$ & $\begin{array}{l}k_{1}=1.6 \times 10^{-10} \\
k_{2}=1.0 \times 10^{-10} \\
k_{3}=9.4 \times 10^{-10} \\
k_{4}=1.9 \times 10^{-7}\left(300 / T_{e}\right)^{05} \\
k_{5}=3.8 \times 10^{-7} \\
k_{6}=1.2 \times 10^{-10} \\
k_{7}=5 \times 10^{-11} \\
k_{8}=7.7 \times 10^{-10} \\
k_{9}=1.4 \times 10^{-10}\left(300 / T_{n}\right) \\
k_{10}=3.5 \times 10^{-7}\left(300 / T_{e}\right)^{0.5} \\
k_{11}=7.4 \times 10^{-11} \\
k_{12}=4.6 \times 10^{-10} \\
k_{13}=2.2 \times 10^{-11} \\
k_{14}=1.1 \times 10^{-9} \\
k_{15}=2.3 \times 10^{-7}\left(300 / T_{e}\right)^{05} \\
k_{16}=4.4 \times 10^{-10} \\
k_{17}=1.1 \times 10^{-9} \\
k_{18}=1.1 \times 10^{-9}\end{array}$ & $\begin{array}{l}1.33 \\
0.13 \\
1.20 \\
4.76 \\
4.56 \\
4.51 \\
1.71 \\
1.81 \\
0.94 \\
3.44 \\
1.57 \\
1.97 \\
0.18 \\
0.78 \\
0.38 \\
2.71 \\
2.91 \\
0.24\end{array}$ & $\begin{array}{l}\text { Fehsenfeld et al. }[1970] \\
\text { Fehsenfeld et al. }[1970] \\
\text { Smith et al. [1978] } \\
\text { Mul and McGowan [1979] } \\
\text { Weller and Biondi }[1967] \\
\text { Fehsenfeld et al. }[1970] \\
\text { Fehsenfeld et al. [1970] } \\
\text { Smith et al. [1978] } \\
\text { McFarland et al. [1974] } \\
\text { Mul and McGowan [1979] } \\
\text { Smith et al. }[1978] \\
\text { Laudenslager et al. [1974] } \\
\text { Laudenslager et al. [1974] } \\
\text { Huntress [1977] } \\
\text { Mul and McGowan [1979] } \\
\text { Lindinger et al. [1975] } \\
\text { Anicich et al. }[1976] \\
\text { Fehsenfeld et al. [1966] }\end{array}$ \\
\hline
\end{tabular}

where $P\left(\mathrm{CO}_{2}^{+}\right)$is the production rate of $\mathrm{CO}_{2}^{+}$ions and $k$, is the rate coefficient of reaction (1) in Table 2 . Reaction with atomic oxygen is the dominant loss mechanism, and $n\left(\mathrm{CO}_{2}{ }^{+}\right)$ is inversely proportional to $n(0)$.

The atomic oxygen abundance was chosen to reproduce the $\mathrm{CO}_{2}^{+}$density at $130 \mathrm{~km}$. The abundances are consistent to within a factor of 2 with the results of previous ionospheric analyses [McConnell, 1976; McElroy et al., 1976; Hanson et al., 1977; Mantas and Hanson, 1979] and with mixing ratios derived from airglow data on atomic oxygen emission lines at 1304, 1356, and $2972 \AA$ [Thomas, 1971; Strickland et al., 1972, 1973; Kurt et al., 1974] and on $\mathrm{CO}_{2}{ }^{+}$emission bands [Krasno- polsky, 1975]. The major uncertainty in our derived mixing ratio may lie in the measurement of the rate coefficient of the reaction of $\mathrm{CO}_{2}{ }^{+}$with $\mathrm{O}$ [Fehsenfeld et al., 1970].

The steady state ion concentrations attained by assuming photochemical equilibrium and using the chemical scheme summarized in Table 2 are shown in Figure 5 along with the measured values. Above $220 \mathrm{~km}$ the $\mathrm{O}^{+}$concentrations are determined by diffusion, and we adopted the measured values.

The $\mathrm{CO}_{2}{ }^{+}$and $\mathrm{O}_{2}^{+}$profiles agree well with the Viking measurements, though some slight deviations occur above $200 \mathrm{~km}$. The $\mathrm{CO}_{2}{ }^{+}$densities can be brought into agreement by an appropriate choice of the atomic oxygen density. The calculated

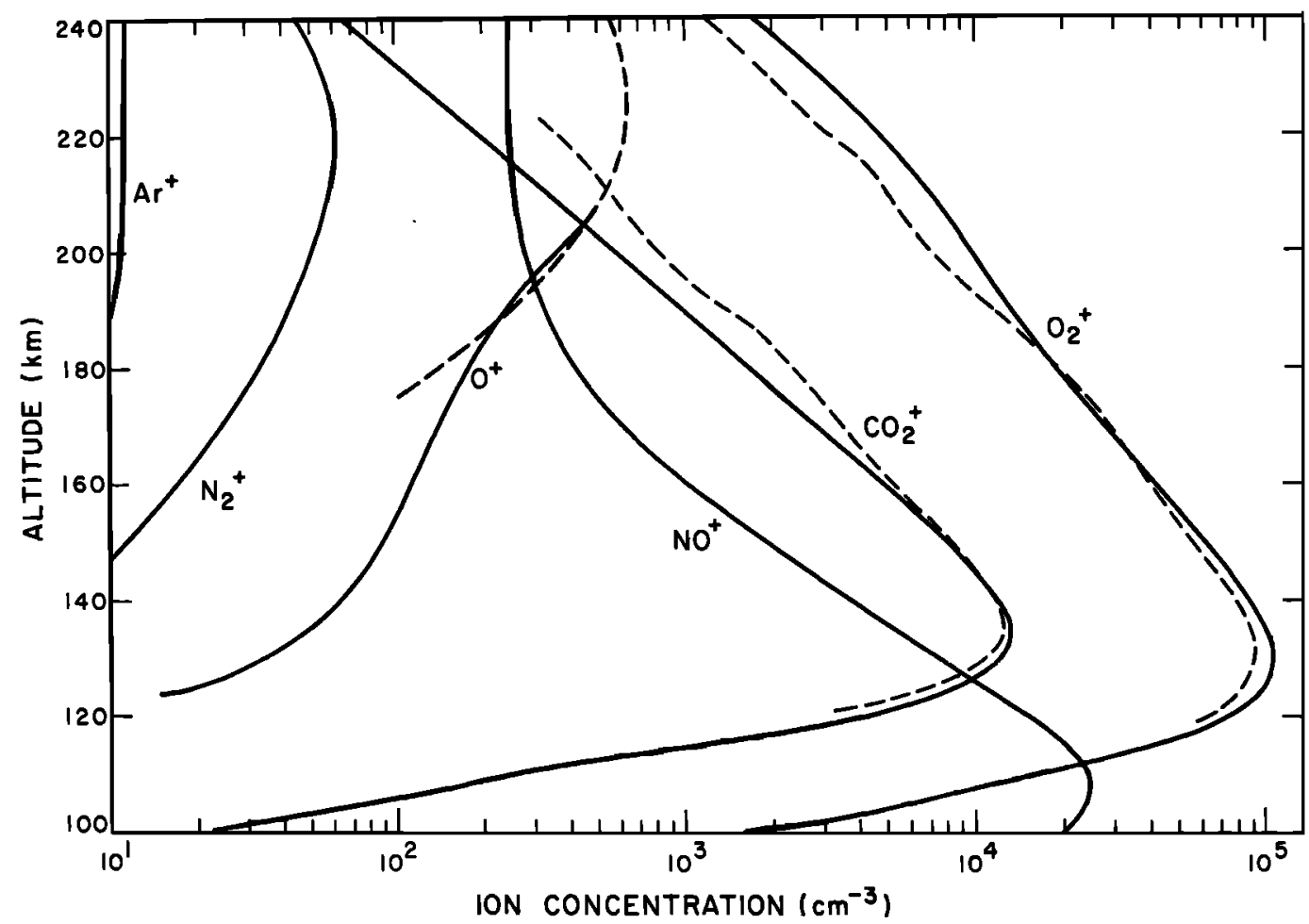

Fig. 5. Steady state ion concentrations. The solid lines are our calculated values. The dashed lines are those measured by Viking 1. 


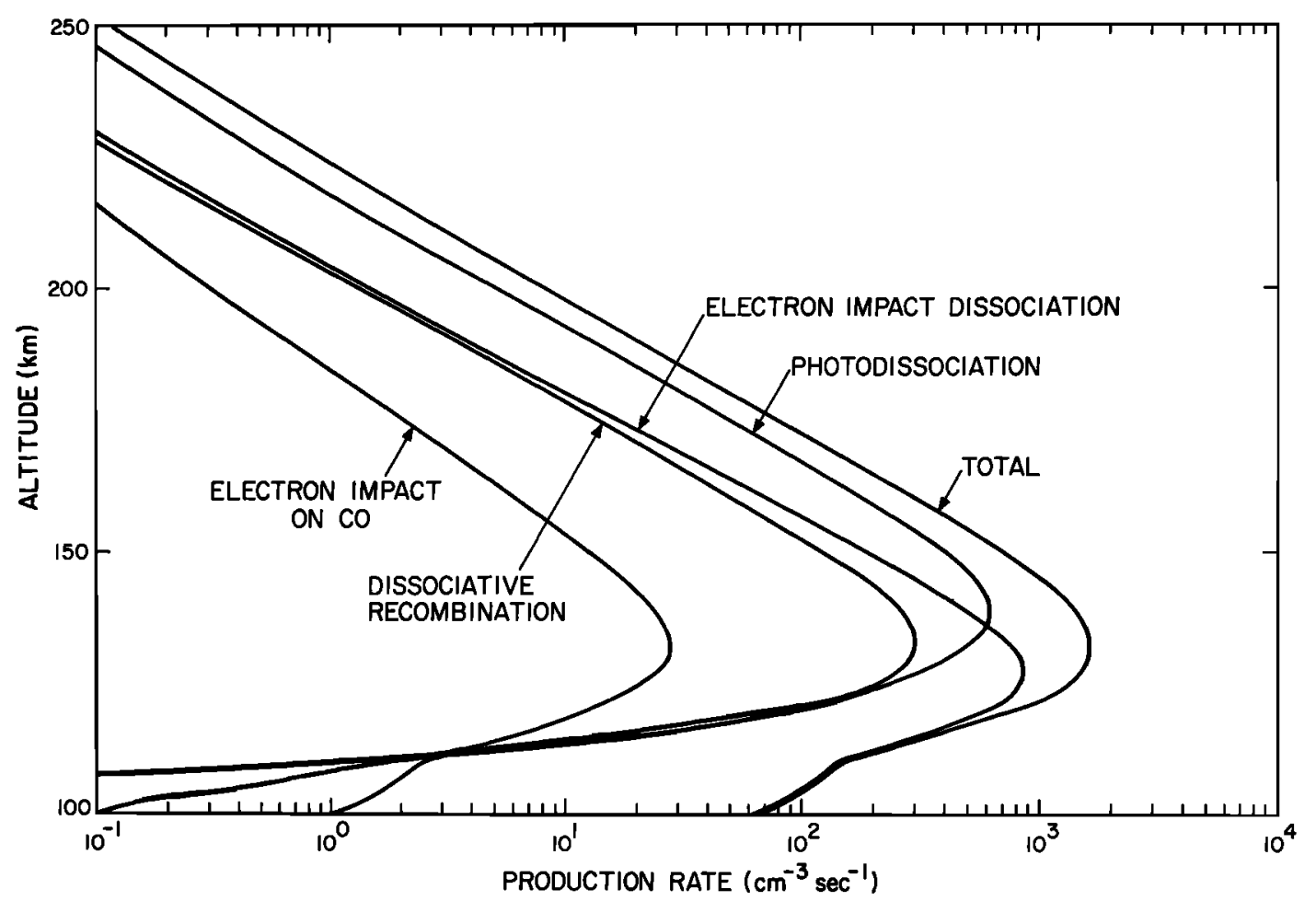

Fig. 6. Computed altitude profiles of the major sources of the Cameron bands $\left(a^{3} \Pi-X^{1} \Sigma\right)$ of $C O$.

$\mathrm{CO}_{2}{ }^{+}$densities at high altitudes are too small because our assumption of diffusive equilibrium overestimates the atomic oxygen concentrations above the ion peak. The close agreement of the $\mathrm{O}_{2}{ }^{+}$concentrations is a consequence of our choice of the electron temperatures and is in part fortuitous. Thus in our calculations of $T_{e}$ we assumed that the heating was local, and we ignored the effects of magnetic fields and solar wind interactions. Transport of photoelectrons tends to enhance $T_{e}$ [Chen et al., 1978]. The transport may be inhibited by horizontal magnetic fields, but such fields also suppress conduction and higher electron temperatures may results [Butler and Stolarski, 1978; Johnson, 1978].

Figure 5 shows also the calculated concentrations of $\mathrm{N}_{2}{ }^{+}$, $\mathrm{No}^{+}$, and $\mathrm{Ar}^{+}$ions, none of which was detected by the $\mathrm{Vi}-$ king experiments. The $\mathrm{N}_{2}{ }^{+}$and $\mathrm{NO}^{+}$ions may be important intermediaries in the escape of nitrogen from the planet [Brinkman, 1971; McElroy, 1972; Yung et al., 1977].

We have not included the reaction of metastable $\mathrm{O}^{+}\left({ }^{2} D\right)$ ions with $\mathrm{N}_{2}$, but it may be a significant source of $\mathrm{N}_{2}{ }^{+}$ions. The photo-ionization of atomic oxygen by solar radiation produces $\mathrm{O}^{+}\left({ }^{2} D\right)$ ions with an efficiency of about $35 \%$. The pro- duction efficiency in the dissociative photo-ionization of $\mathrm{CO}_{2}$ is unknown, but according to Hughes and Tiernan [1971], 4\% of the $\mathrm{O}^{+}$ions resulting from the dissociative ionization of $\mathrm{CO}_{2}$ by impact of $60-\mathrm{eV}$ electrons are formed in the ${ }^{2} \mathrm{D}$ state. The $\mathrm{O}^{+}\left({ }^{2} D\right)$ ions are destroyed by oxygen atoms with a rate coefficient of $\ll 3 \times 10^{-11} \mathrm{~cm}^{3} \mathrm{~s}^{-1}$ [cf. Torr and Orsini, 1978]. The destruction rate of $\mathrm{O}^{+}\left({ }^{2} D\right)$ ions by $\mathrm{CO}_{2}$ is uncertain. If it is small, the $\mathrm{N}_{2}{ }^{+}$densities above $200 \mathrm{~km}$ will be increased by a factor of about 1.7 .

\section{DAYGLOW}

\section{The Cameron Band System of $\mathrm{CO}$}

The Cameron band system of $\mathrm{CO}$ is the strongest feature observed in the ultraviolet Martian dayglow spectra. The system arises from the spin-forbidden transition $a^{3} \Pi-X^{1} \Sigma^{+}$and consists of a number of bands in the region 1800-2600 $\AA$. The possible sources of $\mathrm{CO}\left(a^{3} \Pi\right)$ are [cf. McConnell and McElroy, 1970; Stewart, 1972] photodissociation of $\mathrm{CO}_{2}$,

$$
\mathrm{CO}_{2}+h \nu(\lambda<1082 \AA) \rightarrow \mathrm{CO}\left(a^{3} \Pi\right)+\mathrm{O}
$$

TABLE 3. Overhead Intensities of Airglow Features in Rayleighs

\begin{tabular}{|c|c|c|c|c|c|c|}
\hline \multirow[b]{2}{*}{ Band System } & \multicolumn{5}{|c|}{ Source } & \multirow[b]{2}{*}{ Total } \\
\hline & $\mathbf{a}$ & $\mathbf{b}$ & c & d & e & \\
\hline $\begin{array}{l}\text { CO Cameron } \\
\left(a^{3} \Pi \rightarrow X^{\prime} \Sigma\right)\end{array}$ & 1830 & 2350 & 90 & 650 & $\ldots$ & 4920 \\
\hline $\begin{array}{l}\text { CO fourth positive } \\
\quad\left(A^{\prime} \Pi \rightarrow X^{\prime} \Sigma\right)\end{array}$ & 75 & 62 & 21 & 73 & $\ldots$ & 231 \\
\hline $\begin{array}{l}\mathrm{CO}_{2}^{+} \text {Fox-Duffendack-Barker } \\
\left(A^{2} \Pi_{u} \rightarrow X^{2} \Pi_{g}\right)\end{array}$ & 2035 & 400 & $\cdots$ & $\cdots$ & 840 & 3275 \\
\hline $\begin{array}{l}\mathrm{CO}_{2}^{+} \text {ultraviolet doublet } \\
\quad\left(B^{2} \Sigma_{u}{ }^{+} \rightarrow X^{2} \Pi_{g}\right)\end{array}$ & 925 & 240 & $\cdots$ & $\cdots$ & 45 & 1210 \\
\hline
\end{tabular}

The sources are as follows: a, photodissociation or photo-ionization of $\mathrm{CO}_{2}$; b, electron impact on $\mathrm{CO}_{2}$; c, electron impact on $\mathrm{CO}$; d, dissociative recombination of $\mathrm{CO}_{2}^{+}$; e, fluorescent scattering. 


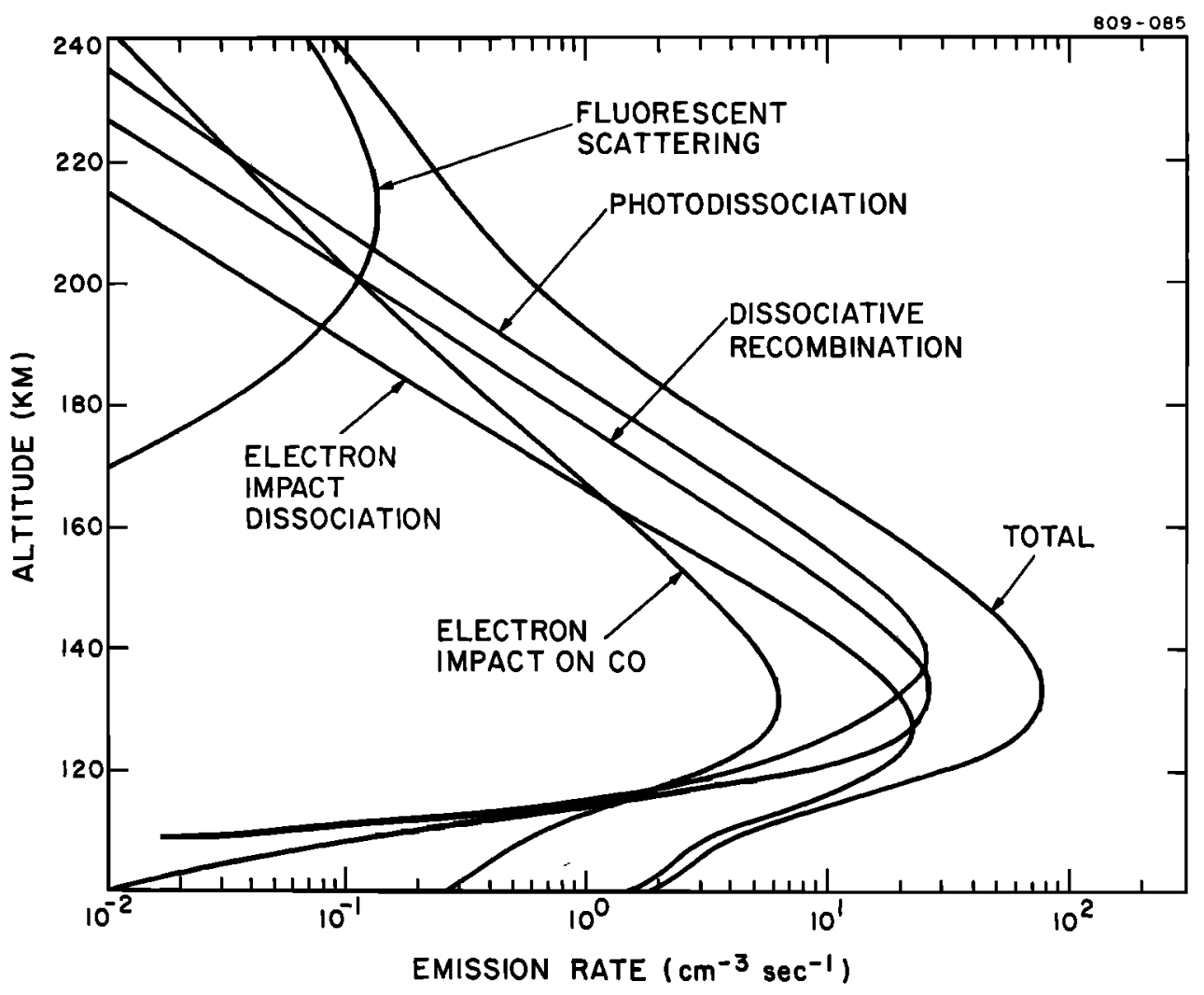

Fig. 7. Computed altitude profiles of the major sources of the fourth positive bands $\left(A^{\prime} \Pi-X^{\prime} \Sigma\right)$ of CO.

photoelectron impact dissociation of $\mathrm{CO}_{2}$,

$$
\mathrm{CO}_{2}+e(E>11.5 \mathrm{eV}) \rightarrow \mathrm{CO}\left(a^{3} \Pi\right)+\mathrm{O}+e
$$

dissociative recombination of $\mathrm{CO}_{2}^{+}$,

$$
\mathrm{CO}_{2}{ }^{+}+e \rightarrow \mathrm{CO}\left(a^{3} \Pi\right)+\mathrm{O}
$$

photoelectron impact excitation of $\mathrm{CO}$,

$$
\mathrm{CO}+e \rightarrow \mathrm{CO}\left(a^{3} \Pi\right)+e
$$

and absorption of sunlight by $\mathrm{CO}$,

$$
\mathrm{CO}+h \nu(\lambda<2030 \AA) \rightarrow \operatorname{CO}\left(a^{3} \Pi\right)
$$

Because there is only a small amount of $\mathrm{CO}$ in the upper atmosphere and because the optical transition is forbidden, fluorescent scattering of sunlight is a negligible source [Stewart, 1972].

On Mariner 6 and 7 the measured Cameron band limb intensities were reported to be in excess of $500 \mathrm{kR}$, but on Mariner 9 the intensity was reduced by a factor of 2.5 , partly because of a decrease in solar activity, but mostly because of the superior calibration of the instrument [Stewart et al., 1972].

We have calculated the Cameron band intensities resulting from the various mechanisms. To calculate the contribution from photoelectron impacts on $\mathrm{CO}_{2}$, we followed the analysis of electron energy degradation in $\mathrm{CO}_{2}$ by Fox and Dalgarno [1979]. To calculate the contribution from photodissociation, we adopted the branching ratios of Lawrence [1972a], and for the contribution from dissociative recombination we adopted the branching ratios measured by Wauchop and Broida [1972]. To calculate the contribution from photoelectron impact excitation of CO, we used the cross sections of Ajello [1971].

The altitude profiles of the various sources are shown in Figure 6, and the integrated intensities are presented in Table
3. The total overhead intensity for a solar zenith angle of $45^{\circ}$ is about $5 \mathrm{kR}$. Mariner 9 subsolar zenith intensities are of the order of $12 \mathrm{kR}$ or $8 \mathrm{kR}$ for a solar zenith angle of $45^{\circ}$. Most of the discrepancy can be attributed to differences in solar activity. The Hinteregger R74113 flux that we used was measured on a day during which the Ottawa $10.7-\mathrm{cm}$ flux, $F_{10.7}$, was 74 [Hinteregger, 1976]. These fluxes are appropriate to Viking 1 solar conditions $\left(F_{10.7}=69.4\right)$. Mariner 9 began to record spectra in a period of higher solar activity. $F_{10.7}$ for November 14, 1971, was 101.1. Stewart et al. [1972] have found that the subsolar zenith intensity $I$ of the Cameron band is apparently related to the $10.7-\mathrm{cm}$ flux index by

$$
I=0.062\left(74+F_{107}\right) \mathrm{kR}
$$

For $F_{107}=70, I$ is about $9 \mathrm{kR}$, or about $6.5 \mathrm{kR}$ for a solar zenith angle of $45^{\circ}$. The agreement with our calculated value of $5 \mathbf{k R}$ is satisfactory.

The major source of the emission below $135 \mathrm{~km}$ is electron impact dissociation of $\mathrm{CO}_{2}$. Above $135 \mathrm{~km}$, photodissociation is more important. The integrated intensities given in Table 1 show that electron impact dissociation and photodissociation are the largest sources. Dissociative recombination contributes less than $15 \%$, and electron impact on $\mathrm{CO}$ less than $2 \%$. In agreement with the calculated contributions the vibrational distribution is consistent with that observed in laboratory spectra produced by impact of $20-\mathrm{eV}$ electrons of $\mathrm{CO}_{2}$ and with that anticipated from photodissociation of $\mathrm{CO}_{2}$ [Barth et al., 1971].

\section{The Fourth Positive System of $\mathrm{CO}$}

The fourth positive band system arises from the $A^{1} \Pi-X^{1} \Sigma$ transition. The threshold for excitation of $\mathrm{CO}$ to the $A^{\prime} \Pi$ state is $8.02 \mathrm{eV}$, and the threshold for dissociative excitation of $\mathrm{CO}_{2}$ 


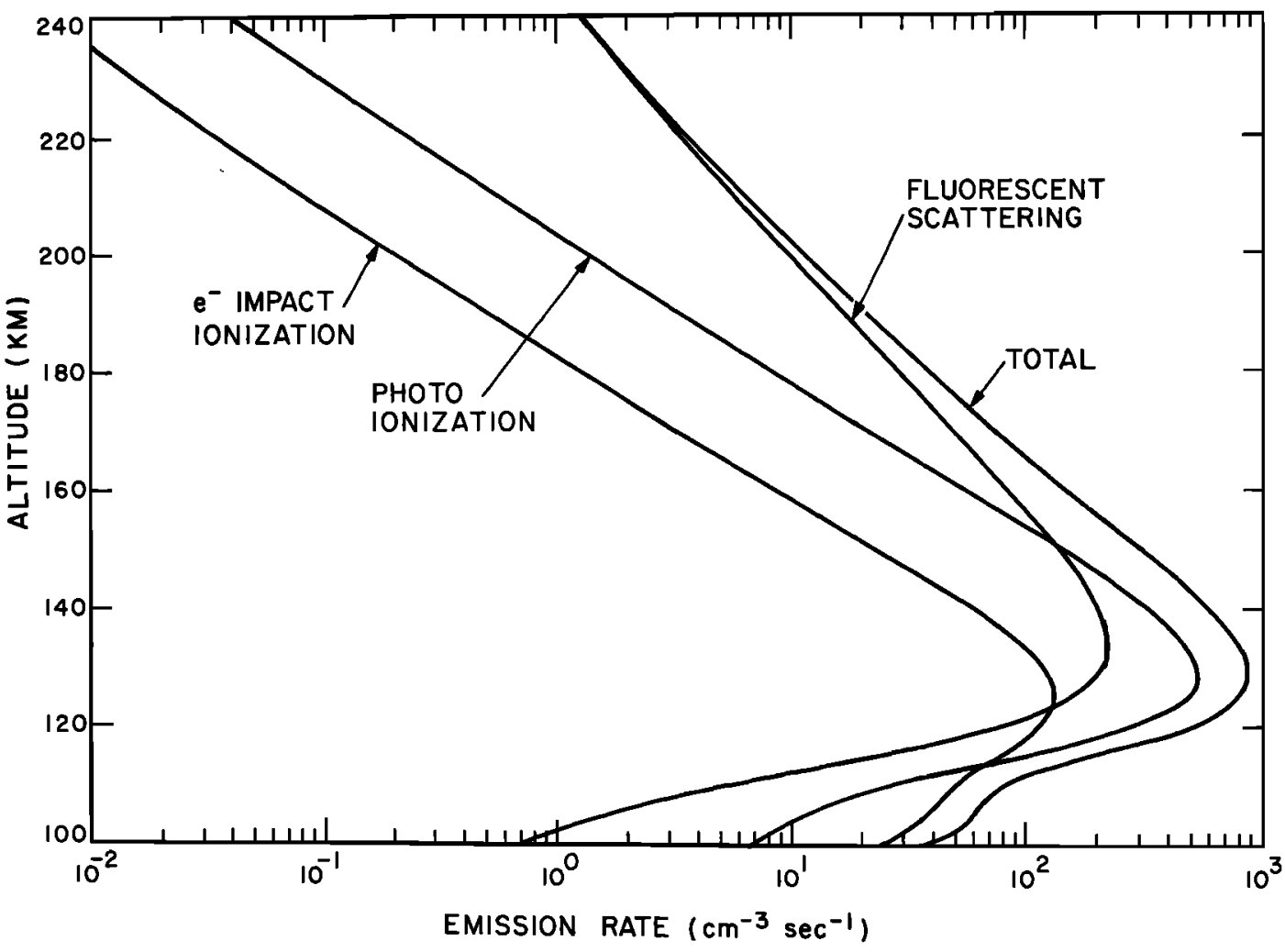

Fig. 8. Computed altitude profiles of the major sources of the $\mathrm{CO}_{2}{ }^{+}$Fox-Duffendack-Barker bands $\left(A^{2} \Pi_{u}-X^{2} \Pi_{g}\right)$.

to the $A^{\prime} \Pi$ state of $\mathrm{CO}$ is $13.5 \mathrm{eV}$. The mechanisms that populate the $A^{\prime} \Pi$ state are similar to those listed for the $a^{3} \Pi$ state.

Cross sections for electron impact excitation of $\mathrm{CO}$ have been measured by Mumma et al. [1971]. The branching ratio leading to the $A^{\prime} \Pi$ state by dissociative recombination of $\mathrm{CO}_{2}{ }^{+}$has been derived by Gutchek and Zipf [1973] and the branching ratio for photodissociation of $\mathrm{CO}_{2}$ by Gentieu and Mentall [1973]. The efficiencies with which electrons absorbed in a partly ionized gas of $\mathrm{CO}_{2}$ populate the $A^{\prime} \Pi$ states of $\mathrm{CO}$ have been computed by Fox and Dalgarno [1979]. The efficiency of flourescent scattering of sunlight by ground state $\mathrm{CO}$ molecules in producing excited $A^{\prime} \Pi$ molecules may be calculated from the absolute transition probabilities of Mumma et al. [1971] and the solar fluxes of Hinteregger [1976]. We obtain a scattering efficiency for each molecule of $\mathrm{CO}$ of $3.2 \times 10^{-7}$ in the optically thin limit.

The absorption cross section at the line center is of the order of $10^{-13} \mathrm{~cm}^{2}$, and absorption of the incident solar photons limits the contribution of fluorescent scattering of sunlight to less than $1 \mathrm{R}$. That fluorescence is a small excitation source is consistent with the observations, which indicate a scale height for the emission similar to that of the $\mathrm{CO}_{2}$ altitude distribution [Barth et al., 1971; Stewart, 1972].

Figure 7 shows the altitude profiles and Table 3 lists the intensities of the fourth positive band system resulting from the various sources. The bands terminating in the $v^{\prime \prime}=0$ level of the $X^{\prime} \Sigma$ state are absorbed in the atmosphere [Barth et al., 1971], and the absorbed energy is radiated in the other bands of the system. There is no loss in the intensity of the emission and only a small modification of the altitude profile. The total overhead intensity is $210 \mathrm{R}$. Differences between the adopted and the actual solar flux incident at the time of the measurements might increase the predicted value to $450 \mathrm{R}$, but there remains a substantial discrepancy between the calculated intensity and the measured limb intensity which is equivalent to an overhead intensity of about $1 \mathbf{~ k R}$.

In an earlier study, McConnell [1973] was unable to reproduce the Mariner 9 intensity profile with the photodissociation and electron impact dissociation sources, and McElroy [1973] suggested that inclusion of dissociative recombination of $\mathrm{CO}_{2}^{+}$would resolve the discrepancy. We find the three sources to provide comparable contributions, and the discrepancy may arise instead from a combination of errors in the molecular branching ratios and uncertainties in the calibration of the Mariner 9 spectra.

The $\mathrm{CO}_{2}{ }^{+} A^{2} \Pi_{w}-X^{2} \Pi_{g}$ and $B^{2} \Sigma_{w}{ }^{+}-X^{2} \Pi_{g}$ Band Systems

Emissions from the $A^{2} \Pi_{u}$ and $B^{2} \Sigma_{u}^{+}$states of $\mathrm{CO}_{2}^{+}$are prominent features of the Martian dayglow. The Fox-Duffendack-Barker $\left(A^{2} \Pi_{u}-\chi^{2} \Pi_{g}\right)$ system consists of several narrow bands between 2800 and $5000 \AA$. The $(0,0,0)-(0,0,0)$ transition of the $B^{2} \Sigma_{u}{ }^{+}-X^{2} \Pi_{\mathrm{g}}$ system produces the ultraviolet doublet at 2883 and $2896 \AA$. Both transitions are excited by photo-ionization of $\mathrm{CO}_{2}$, electron impact ionization of $\mathrm{CO}_{2}$, and fluorescent scattering of sunlight by $\mathrm{CO}_{2}{ }^{+}$.

The cross sections for production of the $A$ and $B$ states of $\mathrm{CO}_{2}{ }^{+}$by electron impact ionization have been summarized by Fox and Dalgarno [1979]. The excitation rates for fluorescent scattering were calculated by using McCallum and Nicholls' [1972] transition probabilities, normalized to the lifetimes measured by Schlag et al. [1977]. The continuum solar fluxes were taken from Heath and Thekaekara [1977] and from Pierce and Allen [1977]. At Mars the scattering factor is $1.7 \times$ $10^{-2}$ for excitation of the $A^{2} \Pi_{u}$ state and $9.1 \times 10^{-4}$ for excitation of the $B^{2} \Sigma_{u}^{+}$state. 


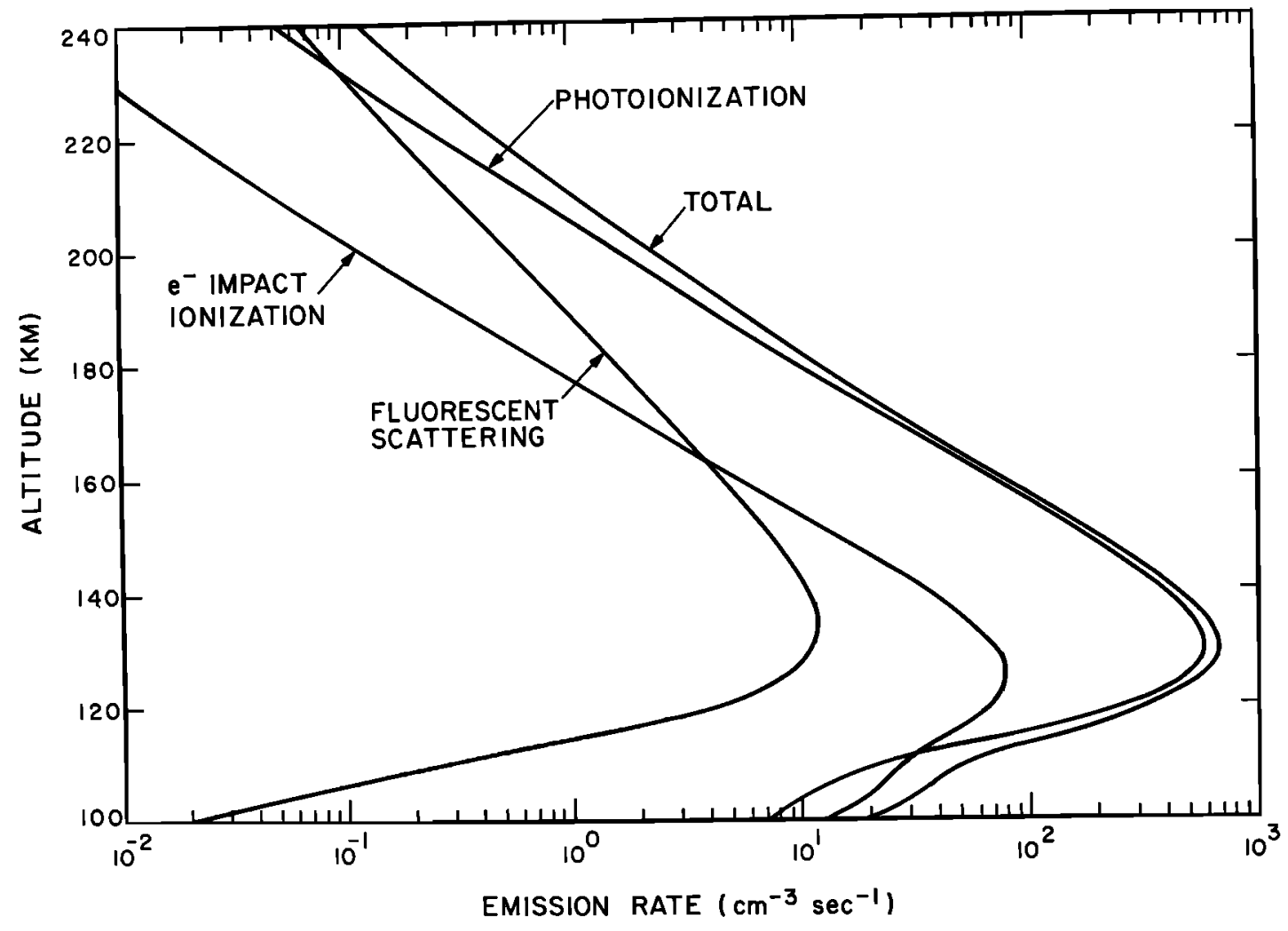

Fig. 9. Computed altitude profiles of the major sources of the $\mathrm{CO}_{2}{ }^{+}$ultraviolet doublet $\left(B^{2} \Sigma_{u}{ }^{+}-X^{2} \Pi_{g}\right)$.

There has been some confusion in the literature over the production of the $A$ and $B$ states of $\mathrm{CO}_{2}{ }^{+}$by photo-ionization of $\mathrm{CO}_{2}$. Measurements using the technique of photoelectron spectroscopy [Samson and Gardier, 1973a] lead to a branching ratio different from that obtained by fluorescence measurements [Wauchop and Broida, 1972; Lee and Judge, 1972; Leach et al., 1978a]. The resolution lies in a mixing of the $A$ and $B$ states that occurs before emission [Samson and Gardner, 1973a; Leach et al., 1978b]. We assume that 0.5 of the absorption into the $B$ state lead to emission in the $A$ state, an assumption which is consistent with the measured fluorescence ratio of 2.2 for absorption of 584- $\AA$ radiation.

The altitude profiles of the emissions resulting from photoionization, photoexcitation, and fluorescent scattering are shown in Figures 8 and 9, and the integrated intensities are given in Table 3. The largest source of both the $A-X$ and the $B$-X emissions is photo-ionization of $\mathrm{CO}_{2}$, consistent with the conclusion of Barth et al. [1972] that the measured vibrational distribution of the $\mathrm{CO}_{2}^{+}$systems is appropriate to photo-ionization. Electron impact excitation accounts for less than $15 \%$ of the observed intensity in either band. Fluorescent scattering produces about one fourth of the intensity of the Fox-Duffendack-Barker system but is unimportant for the ultraviolet doublet.

The limb intensities measured on Mariner 9 of the ultraviolet doublet are 50-75 kR, corresponding to a near-subsolar zenith intensity of $3 \mathrm{kR}$ [Stewart et al., 1972]. Our calculated value of $1.2 \mathrm{kR}$ is in acceptable agreement when differences in solar flux are taken into account. A similar agreement exists between the measured and the calculated values of the intensity of the $A-X$ emission. The limb intensity was greater than $140 \mathrm{kR}$, consistent with an overhead intensity of $7 \mathbf{k R}$. Our calculated value at a time of lesser solar activity is $3.3 \mathbf{~ k R}$.

\section{Atomic Oxygen Emissions}

The Mariner 6, 7, and 9 spectra show clearly three features identified with the atomic oxygen emissions at 1304, 1356, and $2972 \AA$. The $1304-\AA$ features is a triplet emission at 1302 , 1304 , and $1306 \AA$ and arises from the transition $O\left({ }^{3} S^{0}\right)-O\left({ }^{3} P\right)$. It is excited mainly by resonance scattering but is also produced by electron impact on $\mathrm{O}$, electron impact dissociation of $\mathrm{CO}_{2}$, and photodissociation of $\mathrm{CO}_{2}$. The latter three sources are important at altitudes less than about $200 \mathrm{~km}$, while resonance scattering produces a maximum near $500-700 \mathrm{~km}$ [Barth et al., 1971]. We calculate the lower altitude source.

The doublet at 1356 and $1358 \AA$ is produced by the ${ }^{5} S^{0}-{ }^{3} P$ transition. The ${ }^{5} S^{0}$ state is excited by the same mechanisms as the ${ }^{3} S^{0}$ state, but because the transition is forbidden, resonance scattering is not important. The $2972-\AA$ line is due to the forbidden transition, $O\left({ }^{1} S\right)-O\left({ }^{3} P\right)$. Although the ${ }^{1} S$ state is metastable, it is not efficiently quenched above $100 \mathrm{~km}$. Of the $O\left({ }^{1} S\right)$ atoms produced, a fraction $(0.95)$ radiate to the $O\left({ }^{1} D\right)$ state and thus produce the 5577- $\AA$ oxygen green line. Radiation from the $O\left({ }^{1} D\right)$ state produces the oxygen red line at 6300 $\AA$, but the emission is weak because most of the $O\left({ }^{1} D\right)$ atoms are quenched before they can radiate. Although neither the $5577-\AA$ nor the $6300-\AA$ emission has been measured in the Martian dayglow, the emission rates are important to the energy balance in the atmosphere. The metastable atoms $O\left({ }^{\prime} S\right)$ and $O\left({ }^{1} D\right)$ are produced by the same mechanisms as $O\left({ }^{5} S^{0}\right)$ and also by dissociative recombination of $\mathrm{O}_{2}{ }^{+}$.

Cross sections for electron impact on atomic oxygen have been compiled by Dalgarno and Lejeune [1971]. The production of excited oxygen atoms by electron impact on $\mathrm{CO}_{2}$ has been analyzed by Fox and Dalgarno [1979]. Gentieu and Mentall [1973] have given an upper limit to the photodissociation branching ratio for the production of the ${ }^{3} S^{0}$ state, but no in- 
TABLE 4. Excitation Rates of Excited States of Atomic Oxygen

\begin{tabular}{cccccr}
\hline & \multicolumn{5}{c}{ Excitation Rates, $10^{6} \mathrm{~cm}^{-2} \mathrm{~s}^{-1}$} \\
\cline { 2 - 5 } State & $\begin{array}{c}\text { Photodis- } \\
\text { sociation } \\
\text { of } \mathrm{CO}_{2}\end{array}$ & $\begin{array}{c}\text { Electron } \\
\text { Impact } \\
\text { Dissociation } \\
\text { of } \mathrm{CO}_{2}\end{array}$ & $\begin{array}{c}\text { Electron } \\
\text { Impact } \\
\text { Excitation } \\
\text { of } \mathrm{O}\end{array}$ & $\begin{array}{c}\text { Dissociative } \\
\text { Recombination } \\
\text { of } \mathrm{O}_{2}^{+}\end{array}$ & Total \\
\hline$O\left({ }^{1} S\right)$ & 13,600 & 704 & 45 & 850 & 15,200 \\
$O\left({ }^{(} D\right)$ & 114,000 & 130 & 787 & 7,650 & 123,000 \\
$O\left({ }^{3} S\right)$ & 1.4 & 4.2 & 12. & & 17.6 \\
$O\left({ }^{5} S\right)$ & & 8.7 & 37 & 46 \\
\hline
\end{tabular}

formation is available concerning the production of $O\left({ }^{5} S^{0}\right)$. The branching ratios of $O\left({ }^{1} S\right)$ and $O\left({ }^{\prime} D\right)$ have been measured by Lawrence [1972b] and by Slanger and Black [1971], and the yields of $O\left({ }^{\prime} S\right)$ and $O\left({ }^{\prime} D\right)$ from dissociative recombination of $\mathrm{O}_{2}{ }^{+}$have been given by Zipf [1970] and by analysis of terrestrial data [cf. Bates, 1978; Hays et al., 1978].

The integrated rates for the production of various excited states of atomic oxygen are shown in Table 4 . The altitude profiles for excitation of the ${ }^{3} S^{0}$ and ${ }^{5} S^{0}$ states are shown in Figure 10. The emitted photons are absorbed by $\mathrm{CO}_{2}$. For the $1356-\AA$ radiation we calculate a zenith intensity of $46 \mathrm{R}$ after having taken into account the absorption by $\mathrm{CO}_{2}$. The intensity is high in comparison to the Mariner $9 \mathrm{limb}$ intensity of $500 \mathrm{R}$. The discrepancy suggests that the measured electron impact cross sections of atomic oxygen [Stone and Zipf, 1974] are too large. To obtain agreement, the cross sections must be reduced by about a factor of 3 .

In our model the ${ }^{3} S^{0}$ and ${ }^{5} S^{0}$ states are excited primarily by electron impact on atomic oxygen. In contrast, McConnell [1973] concluded that electron impact dissociation of $\mathrm{CO}_{2}$ is the major source of $1356-\AA$ radiation, on the basis of a cross section for electron impact on atomic oxygen derived from terrestrial airglow profiles. Our $O\left({ }^{5} S^{0}\right)$ excitation rate due to electron impact dissociation is only one fourth of that due to direct excitation of atomic oxygen. If the measured cross section is too large by a factor of 3 , as was suggested by the 1356$\AA$ data, the two sources are comparable. None of the sources considered for excitation of $\mathrm{O}\left({ }^{3} S^{0}\right)$ atoms is significant in comparison to resonance scattering of sunlight.

The total excitation rates of $O\left({ }^{1} D\right)$ and $O\left({ }^{1} S\right)$ are given in Table 4, and the altitude profiles are shown in Figures 11 and 12. The altitude profile for $O\left({ }^{1} S\right)$ production shows two peaks, one at $130 \mathrm{~km}$ and another near $90 \mathrm{~km}$. The $130-\mathrm{km}$ peak is due to the absorption of solar photons in the 1100 - to $1140-\AA$ region, where the absorption cross section is large and the $O(' S)$ yield is unity. The lower peak is due the absorption of Lyman alpha at 1216- $\AA$; the absorption coefficient at this wavelength is 2 orders of magnitude less than the absorption coefficients in the 1100 - to $1140-\AA$ region, and the yield of $O(' S)$ is about 0.1 . The $O\left({ }^{\prime} D\right)$ photodissociation profile shows

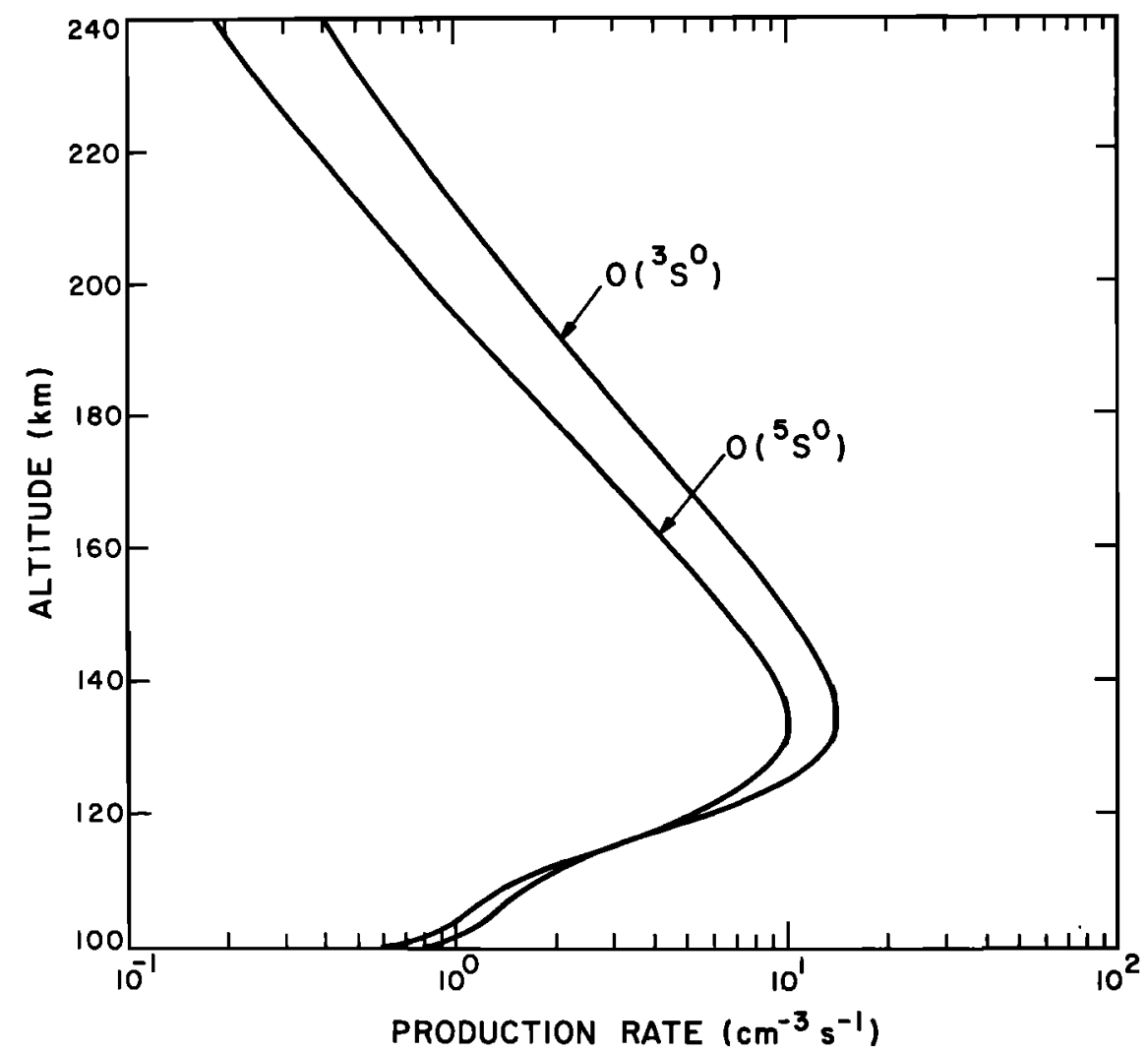

Fig. 10. Computed altitude profiles of the total production rates of $O\left({ }^{3} S^{0}\right)$ and $O\left(s^{5}\right)$. The major source of each state is electron impact excitation of atomic oxygen. 


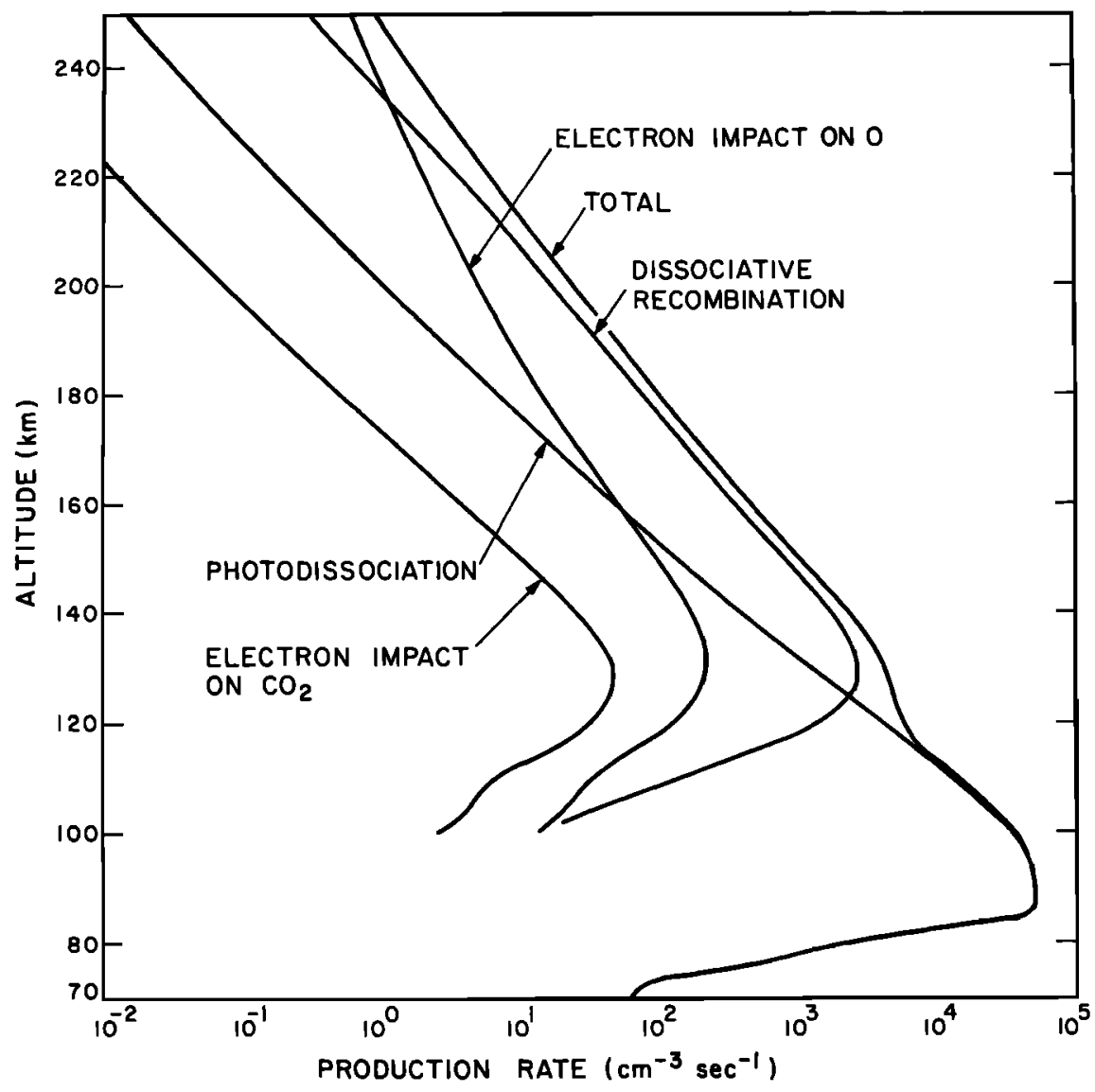

Fig. 11. Computed altitude profiles of the major sources of $O\left({ }^{\prime} D\right)$.

only a single peak near $90 \mathrm{~km}$ due to the absorption of longwavelength photons. The total production rate exhibits a higher-altitude peak due to dissociative recombination of $\mathrm{O}_{2}{ }^{+}$.

Emissions of the 2972-, 5577-, and 6300- $\AA$ lines are diminished by the loss of the metastable atoms through quenching reactions. Heidner and Husain [1973] have measured the rate constants for quenching of $\mathrm{O}\left({ }^{\prime} D\right)$ by $\mathrm{CO}_{2}, \mathrm{~N}_{2}, \mathrm{CO}$, and $\mathrm{O}_{2}$, and Streit et al. [1976] have measured rate coefficients for quenching by $\mathrm{N}_{2}, \mathrm{O}_{2}$, and $\mathrm{CO}_{2}$. Slanger and Black [1976] have given quenching coefficients for the reaction of $O\left({ }^{1} S\right)$ with $\mathrm{CO}_{2}$ and $\mathrm{O}$, and Atkinson and Welge [1972] have shown that quenching of $O\left({ }^{1} S\right)$ and $N_{2}$ is slow. The total emission rates of the three lines are given as follows:

$\begin{array}{cc}\frac{\text { Line, } \AA}{2972} & \text { Emission Rate, R } \\ 5577 & 638 \\ 6300 & 12,700 \\ 145\end{array}$

and Figure 13 shows the corresponding altitude profiles. The emission rates of the 2972- and 5577- $\AA$ lines follow closely the production rates of $O(' S)$ as a function of altitude, since $O\left({ }^{\prime} S\right)$ is not efficiently quenched. The $6300-\AA\left({ }^{1} D-^{3} P\right)$ emission is weak at all altitudes because of efficient quenching of $O\left({ }^{1} D\right)$. The total overhead intensity of $2972-\AA$ radiation is about 640 $R$ compared to the Mariner 6 and 7 maximum limb intensity of $20 \mathrm{kR}$, corresponding to an overhead intensity of $1 \mathrm{kR}$. We find that photodissociation is the major source, in agreement with the prediction of Barth et al. [1971], based on the scale heights of the Mariner 6 and 7 data.

\section{Atomic Carbon Emissions}

The resonance lines of atomic carbon at 1561 and $1657 \AA$ are observed in the Mariner 6, 7, and 9 spectra. The emitting levels may be populated by photodissociation of $\mathrm{CO}_{2}$ and by electron impact dissociation of $\mathrm{CO}_{2}$.

Photodissociation cross sections for the production of the 1561- and 1657- $\AA$ lines from the threshold wavelength to 420 $\AA$ have been reported by $W u$ et al. [1978]. Below $420 \AA$ we arbitrarily assumed a constant branching ratio for each line equal to that appropriate at longer wavelengths, where the total cross section for fluorescence has been measured by Lee et al. [1975]. The production of $C 1561 \AA$ and $1657 \AA$ by energetic electrons absorbed in $\mathrm{CO}_{2}$ has been studied by Fox and Dalgarno [1979], and we adopted their results.

The resulting overhead intensities from photodissociation of $\mathrm{CO}_{2}$ and electron impact dissociation are presented in Table 5. The two sources provide $15 R$ of $1657-\AA$ radiation and $8 \mathrm{R}$ of $1561-\AA$ radiation. Earlier calculations by McElroy and McConnell [1971], which gave somewhat higher values, were based upon less accurate molecular data.

The measured intensity of the $1657-\AA$ emission corresponds to an overhead intensity of about $100 \mathrm{R}$, and an additional source must be invoked. Photodissociation and electron impact dissociation are insignificant sources, but resonance scattering of sunlight by atomic carbon may be effective [McElroy and Mc Connell, 1971].

McElroy and McConnell [1971] have discussed the production of atomic carbon in the atmosphere of Mars. They calculated that $10 \mathrm{R}$ of $1657-\AA \AA$ emission could be provided by reso- 


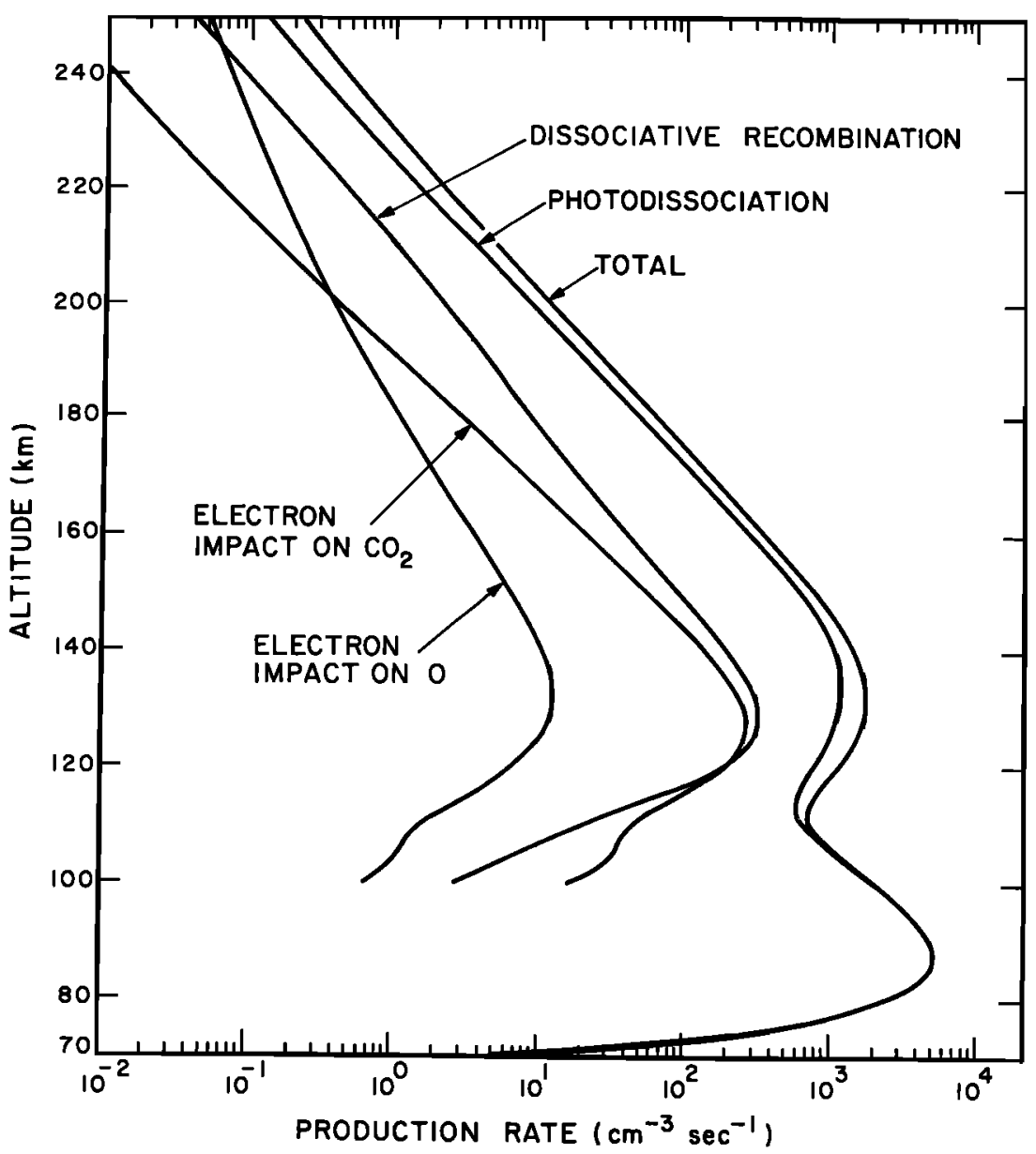

Fig. 12. Computed altitude profiles of the major sources of $O\left({ }^{1} S\right)$.

nance scattering and concluded that dissociation of $\mathrm{CO}_{2}$ was the major source of the emission.

Our calculations show that dissociation of $\mathrm{CO}_{2}$ is not a large enough source and suggest that the abundance of atomic carbon calculated by McElroy and McConnell [1971] should be increased by an order of magnitude. McElroy and McConnell remarked that their analysis tended to underestimate the abundance of atomic carbon.

\section{Molecular Nitrogen Emissions}

No evidence for the existence of atomic or molecular nitrogen or nitric oxide was found in the Mariner 6, 7, or 9 dayglow spectra. Dalgarno and McElroy [1970] calculated a maximum nitrogen mixing ratio of $5 \%$ in the Martian atmosphere, assuming that a dayglow intensity of $50 \mathrm{R}$ might have escaped detection. The mixing ratio measured by Viking 1 is about $2.5 \%$ in the upper atmosphere.

Features of interest are the Vegard-Kaplan bands $\left(A^{3} \Sigma_{u}{ }^{+}\right.$

TABLE 5. Overhead Intensities of Lines of Neutral and Ionized Carbon Due to Electron Impact Dissociation and Photodissociation of $\mathrm{CO}_{2}$

\begin{tabular}{ccc}
\hline & \multicolumn{2}{c}{ Overhead Intensities } \\
\cline { 2 - 3 } Line, $\AA$ & Electron Impact & Photodissociation \\
\hline C I 1329 & 1.5 & $\ldots$ \\
C I 1657 & 9.0 & 6.0 \\
C I 1561 & 5.0 & 3.0 \\
C II 1335 & 0.7 & $\cdots$ \\
\hline
\end{tabular}

$\left.X^{1} \Sigma_{g}^{+}\right)$, the second positive bands $\left(C^{3} \Pi_{\mu}-B^{3} \Pi_{g}\right)$ and LymanBirge-Hopfield bands $\left(a^{1} \Pi_{\mathrm{g}}-X^{1} \Sigma_{g}{ }^{+}\right)$of molecular nitrogen, and the first negative bands $\left(B^{2} \Pi_{u}^{+}-X^{2} \Sigma_{g}{ }^{+}\right)$of $\mathrm{N}_{2}{ }^{+}$. The nitrogen first positive $\left(B^{3} \Sigma_{g}-A^{3} \Sigma_{u}{ }^{+}\right)$and reverse first positive $(A-B)$ and the $W^{3} \triangle_{u}-B^{3} \Pi_{g}$ and $B-W$ bands emit in the infrared but are important in populating the $A^{3} \Sigma_{w}{ }^{+}$state through cascading. The Meinel $\left(A^{2} \Pi_{u}-X^{2} \Sigma_{g}^{+}\right)$bands of $\mathrm{N}_{2}^{+}$also emit in the infrared.

The excited states of molecular nitrogen are produced by electron impact excitation. The cross sections for excitation of the $A, B, C$, and $W$ triplet states and the $a^{1} \Pi_{g}$ state have been taken from Cartwright et al. [1977] and Chutjian et al. [1977]. Higher triplet states have been neglected; higher singlet states are mostly predissociated [Zipf and McLaughlin, 1978]. The $A$ and $B$ states of $\mathrm{N}_{2}{ }^{+}$are produced by photoionization and electron impact ionization. We used the photo-ionization branching ratios of Samson et al. [1977] and the electron impact branching ratios of Green and Barth [1965].

The calculation of the intensities of specific $v^{\prime}-v^{\prime \prime}$ bands and the population rates through cascading involves transition probabilities and Franck-Condon factors. The transition probabilities for the first and second positive systems were taken from Benesch et al. [1966a], for the Vegard-Kaplan and Lyman-Birge-Hopfield systems from Benesch et al. [1966b], and for the $B-W$ and $W-B$ systems from Covey et al. [1973]. Shemansky and Broadfoot [1971] have tabulated transition probabilities and Franck-Condon factors for the Meinel and first negative systems of $\mathrm{N}_{2}{ }^{+}$.

The total direct excitation rates are given in Table 6. The 


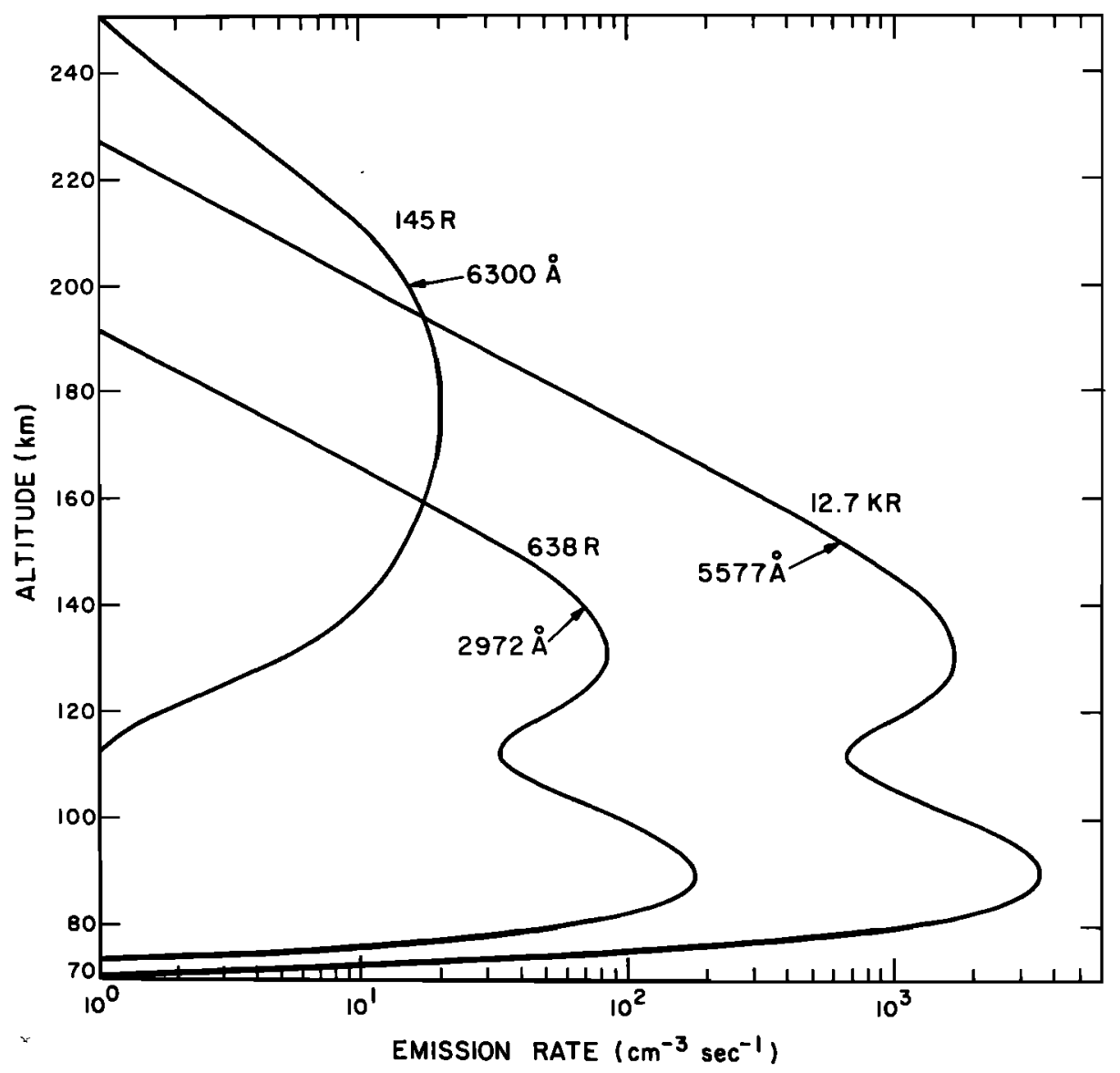

Fig. 13. The total emission rates of the $O\left({ }^{1} S-{ }^{3} P\right) 2972-\AA, O\left({ }^{1} S-1 D\right) 5577-\AA$, and $O\left({ }^{1} D-{ }^{3} P\right) 6300-\AA$ lines.

emission rates of the strongest band systems are given in Table 7. Some of the results have appeared earlier [Fox et al., $1977 a]$. Because of severe quenching by atomic oxygen the Vegard-Kaplan system is weak in the terrestrial airglow, but $\mathrm{CO}_{2}$ does not quench the $A^{3} \Sigma_{u}{ }^{+}$state appreciably [Dreyer et al., 1974], and radiation from it will be relatively stronger in the Martian airglow.

The 1-9 band of the Vegard-Kaplan system has a calculated intensity of $15 \mathrm{R}$. It is located at about $3200 \AA$ and should be visible between the $2-0$ and $3-0$ bands of the FoxDuffendack-Barker system of $\mathrm{CO}_{2}{ }^{+}$. There is no sign of it in the Mariner 6 and 7 spectra, but there is a feature in the published Mariner 9 spectrum near $3200 \AA$ that does not appear in laboratory spectra of pure $\mathrm{CO}_{2}$ [Barth et al., 1971; see Figure 1] and that may be due to this transition.

The $(0,0)$ and $(1,0)$ bands of the $\mathrm{N}_{2}^{+}$Meinel system are strong (22-23 R) but appear in the infrared. The strongest line of the first negative system is the $(0,0)$ transition at $3914 \AA$. It has an intensity of only $9 R$, and it is obscured by the $(0,0,0)$ $(0,0,2)$ band of the $\mathrm{A}-\mathrm{X}$ system of $\mathrm{CO}_{2}{ }^{+}$.

\section{Solar Ultraviolet Heating}

The thermal structure of the upper atmosphere of Mars is affected by gravity waves [Stewart et al., 1972; Krasnopolsky, 1975; Nier and McElroy, 1977], acoustical waves [Krasnopolsky, 1975], solar wind interactions, and solar ultraviolet radiation. We attempt here to calculate the contribution to the heating of the neutral atmosphere arising from the absorption of solar ultraviolet radiation.

Heating occurs by photo-ionization and photodissociation processes. In photo-ionization the excess energy is carried by the ejected electron, which causes further ionization, excitations, and dissociations. In photodissociation, excess energy is carried by the dissociation products and is usually converted directly into thermal energy by elastic collisions with the neutral atmosphere. The ionization and dissociation energies are partly transformed into heat by exothermic ionmolecule and recombination mechanisms. Any metastable atoms and ions produced by photo-ionization, photoelectron impact, photodissociation, and recombination may be quenched by collisions releasing their internal energies as heat.

It is convenient to introduce a heating efficiency $\epsilon$, defined as the fraction of solar ultraviolet energy absorbed that appears locally as thermal energy. For the heating efficiency of ionizing radiation in the Martian ionosphere, Henry and McElroy [1968] have calculated an average value of 0.59 and

TABLE 6. Excitation Rates of Excited States of $\mathbf{N}_{2}$ and $\mathbf{N}_{2}{ }^{+}$

\begin{tabular}{cc}
\hline State & $\begin{array}{c}\text { Excitation Rate, } \\
10^{6} \mathrm{~cm}^{-2} \mathrm{~s}^{-1}\end{array}$ \\
\hline $\mathrm{N}_{2} A^{3} \Sigma_{u}^{+}$ & 93 \\
$B^{3} \Pi_{g}$ & 110 \\
$C^{3} \Pi_{g}$ & 52 \\
$W^{3} \Delta_{u}$ & 91 \\
$a^{1} \Pi_{g}$ & 110 \\
$\mathrm{~N}_{2}^{+}$ & 95 \\
$A^{2} \Pi_{u}$ & 21 \\
$B^{2} \Sigma_{u}^{+}$ & \\
\hline
\end{tabular}


TABLE 7. Calculated Overhead Intensities of $\mathrm{N}_{2}$ and $\mathrm{N}_{2}{ }^{+}$Emission Features

\begin{tabular}{|c|c|c|}
\hline $\begin{array}{c}\text { Band } \\
\left(v^{\prime}-v^{\prime \prime}\right)\end{array}$ & $\underset{\AA}{\text { Band Origin, }}$ & $\underset{\mathbf{R}}{\text { Intensity, }}$ \\
\hline \multicolumn{3}{|c|}{ Vegard-Kaplan $A^{3} \Sigma_{u}{ }^{+}-X^{1} \Sigma_{g}{ }^{+}$} \\
\hline $0-2$ & 2216 & 8 \\
\hline $0-4$ & 2462 & 9 \\
\hline $0-5$ & 2604 & 16 \\
\hline $0-6$ & 2762 & 20 \\
\hline $0-7$ & 2936 & 20 \\
\hline $0-8$ & 3132 & 14 \\
\hline $0-9$ & 3353 & 8 \\
\hline $1-8$ & 2998 & 10 \\
\hline $1-9$ & 3199 & 15 \\
\hline $1-10$ & 3426 & 14 \\
\hline $1-11$ & 3684 & 9 \\
\hline $2-11$ & 3502 & 8 \\
\hline $2-12$ & 3760 & 9 \\
\hline \multicolumn{3}{|c|}{ First Positive $B^{3} \Pi_{g}-A^{3} \Sigma_{u}^{+}$} \\
\hline $0-0$ & $10508.3^{-8}$ & 39 \\
\hline $0-1$ & 12373. & 22 \\
\hline $1-2$ & 11925. & 10 \\
\hline $1-3$ & 14269. & 8 \\
\hline $2-0$ & 7753.7 & 17 \\
\hline $2-1$ & 8723.0 & 24 \\
\hline $3-1$ & 7626.8 & 17 \\
\hline $4-2$ & 7504.7 & 10 \\
\hline \multicolumn{3}{|c|}{$W^{3} \Delta_{u}-B^{3} \Pi_{g}$} \\
\hline $2-0$ & 33260 & 10 \\
\hline $3-0$ & 22528 & 8 \\
\hline $3-1$ & 36580 & 7 \\
\hline $4-1$ & 24160 & 10 \\
\hline $5-1$ & 22084 & 7 \\
\hline \multicolumn{3}{|c|}{ Second Positive $C^{3} \Pi_{4}-B^{3} \Pi_{g}$} \\
\hline $0-0$ & 3370 & 14 \\
\hline $0-1$ & 3576 & 9 \\
\hline $1-0$ & 3158 & 7 \\
\hline \multicolumn{3}{|c|}{ Lyman-Birge-Hopfield $a^{1} \Pi_{\mathrm{g}}-X^{1} \Sigma_{\mathrm{g}}{ }^{+}$} \\
\hline $3-0$ & 1354 & 4 \\
\hline $2-0$ & 1384 & 4 \\
\hline 4-0 & 1325 & 3 \\
\hline $1-1$ & 1464 & 3 \\
\hline $0-2$ & 1555 & 2 \\
\hline $5-0$ & 1299 & 2 \\
\hline \multicolumn{3}{|c|}{ Meinel $A^{2} \Pi_{u}-X^{2} \Sigma_{g}+$} \\
\hline $0-0$ & 11088.4 & 22 \\
\hline $1-0$ & 9182.8 & 23 \\
\hline $2-1$ & 9471.3 & 9 \\
\hline $0-1$ & 14612.3 & 8 \\
\hline $2-0$ & 7853.6 & 8 \\
\hline \multicolumn{3}{|c|}{ First Negative $B^{2} \Sigma_{u}{ }^{+}-X^{2} \Sigma_{g}{ }^{+}$} \\
\hline $0-0$ & 3911.4 & 9 \\
\hline
\end{tabular}

Stewart [1972] an average value of 0.3. For the heating efficiency of dissociating radiation at an altitude of $100 \mathrm{~km}, \mathrm{Dem}$ bovskii et al. [1976] have calculated an average value between 0.25 and 0.35 depending upon the role of vibrationally excited species.

Empirical values of $\epsilon$ have been derived from measurements of the atmospheric scale heights. The values range from 0.35 [Stewart and Hogan, 1969] to 0.1 [McConnell, 1973; Krasnopolsky, 1975].

\section{Molecular Data}

The direct neutral particle heating that results from electron impact dissociation of $\mathrm{CO}_{2}$ has been calculated by Fox and
TABLE 8. Average Kinetic Energies of Products in Electron Impact Dissociation of $\mathrm{CO}_{2}$

\begin{tabular}{|c|c|}
\hline Process & $\begin{array}{c}\text { Kinetic Energy, } \\
\text { eV }\end{array}$ \\
\hline $\begin{aligned} e+\mathrm{CO}_{2} \rightarrow & \mathrm{CO}\left(X^{1} \Sigma\right)+O\left({ }^{3} P\right) \\
& \mathrm{CO}\left(X^{\prime} \Sigma\right)+O\left({ }^{1} S\right) \\
& \mathrm{CO}\left(a^{3} \Pi\right)+O\left({ }^{3} P\right) \\
& \left.\operatorname{CO}\left(a^{\prime}, d\right)+O{ }^{3} P\right) \\
& \operatorname{CO}(e, f, b, c)+O\left({ }^{3} P\right) \\
& \operatorname{CO}\left(X^{1} \Sigma\right)+O\left({ }^{1} D\right)\end{aligned}$ & $\begin{array}{l}1.0 \\
1.4 \\
0.7 \\
1.0 \\
0.8 \\
1.0\end{array}$ \\
\hline
\end{tabular}

Dalgarno [1979]. We reproduce in Table 8 their estimates of the average kinetic energies of the dissociation products.

We have listed in Table 2 the important ionospheric reactions. We include in it the energies that would be released were each of the molecular systems to be in the lowest vibrational state. In calculating the energies we assumed that 0.9 of the dissociative recombinations of $\mathrm{O}_{2}{ }^{+}$lead to $\mathrm{O}\left({ }^{1} D\right)$ atoms and 0.1 to $O(' S)$ atoms, that 0.56 of the dissociative recombinations of $\mathrm{CO}_{2}^{+}$lead to $\mathrm{CO}\left(a^{3} \Pi\right)$ and 0.44 to $\mathrm{CO}\left(X^{1} \Sigma\right)$, and that each recombination of $\mathrm{N}_{2}^{+}$and of $\mathrm{NO}^{+}$and each reaction of $\mathrm{N}_{2}{ }^{+}$with $\mathrm{O}$ leads to $\mathrm{N}\left({ }^{2} D\right)$.

Branching ratios corresponding to the possible paths for photodissociation of $\mathrm{CO}_{2}$ were constructed from the measurements of Mahan [1960], Clark and Noxon [1970], Inn and Heimerl [1971], Slanger and Black [1971, 1978], Inn [1972], Judge and Lee [1973], and Slanger et al. [1977].

We adopted a quantum yield of unity for the production of $O\left({ }^{\prime} D\right)$ from the threshold at $1670 \AA$ up to the $O\left({ }^{\prime} S\right)$ threshold at $1286 \AA$. Between 1286 and $1135 \AA$ we adopted a quantum yield of 0.5 for each of $O\left({ }^{\prime} D\right)$ and $O(' S)$. Between 1670 and $2275 \AA$ we assumed that photodissociation produced ground state products [Inn and Heimerl, 1971; DeMore and Mosesman, 1971]. We adopted the quantum yields of Judge and Lee [1973] for the production of excited states of CO.

The production and quenching of $O\left({ }^{\prime} S\right)$ and $O\left({ }^{\prime} D\right)$ atoms are discussed in the subsection on atomic oxygen of section 6. Quenching of $O\left({ }^{1} D\right)$ atoms is an important heat source below $200 \mathrm{~km}$.

The major uncertainty in the calculated heating rates is probably the degree of vibrational excitation produced in photodissociation and in chemical reactions. The measurements of Judge and Lee [1973] on the production of the $a^{\prime}$ and $e$ states of $\mathrm{CO}$ show a substantial vibrational population, and Clerc and Barat [1967] have found in flash photolysis experiments on $\mathrm{CO}_{2}$ that the product $\mathrm{CO}$ molecules are vibrationally excited. Slanger and Black [1974] studied electronic vibrational energy transfer of $O\left({ }^{\prime} D\right)$ in $\mathrm{N}_{2}$ and $\mathrm{CO}$ and determined that about $40 \%$ of the available energy was taken up as vibrational energy. Dickinson and Ridley [1977] have suggested that most of the metastable energy is converted to vibrational energy when $O\left({ }^{\prime} D\right)$ is quenched in collisions with $\mathrm{CO}_{2}$.

We have explored three models. For model A we assumed that $10 \%$ and for model B that $50 \%$ of the excess energy appears as vibrational energy that is radiated away. For model $\mathbf{C}$ we assumed that $50 \%$ of the excess energy is lost by radiation and that $100 \%$ of the $O\left({ }^{\prime} D\right)$ energy is lost when it is quenched by $\mathrm{CO}_{2}$.

Results

Given the molecular data, the heat deposited in the Martian atmosphere by the absorption of solar radiation may be ob- 


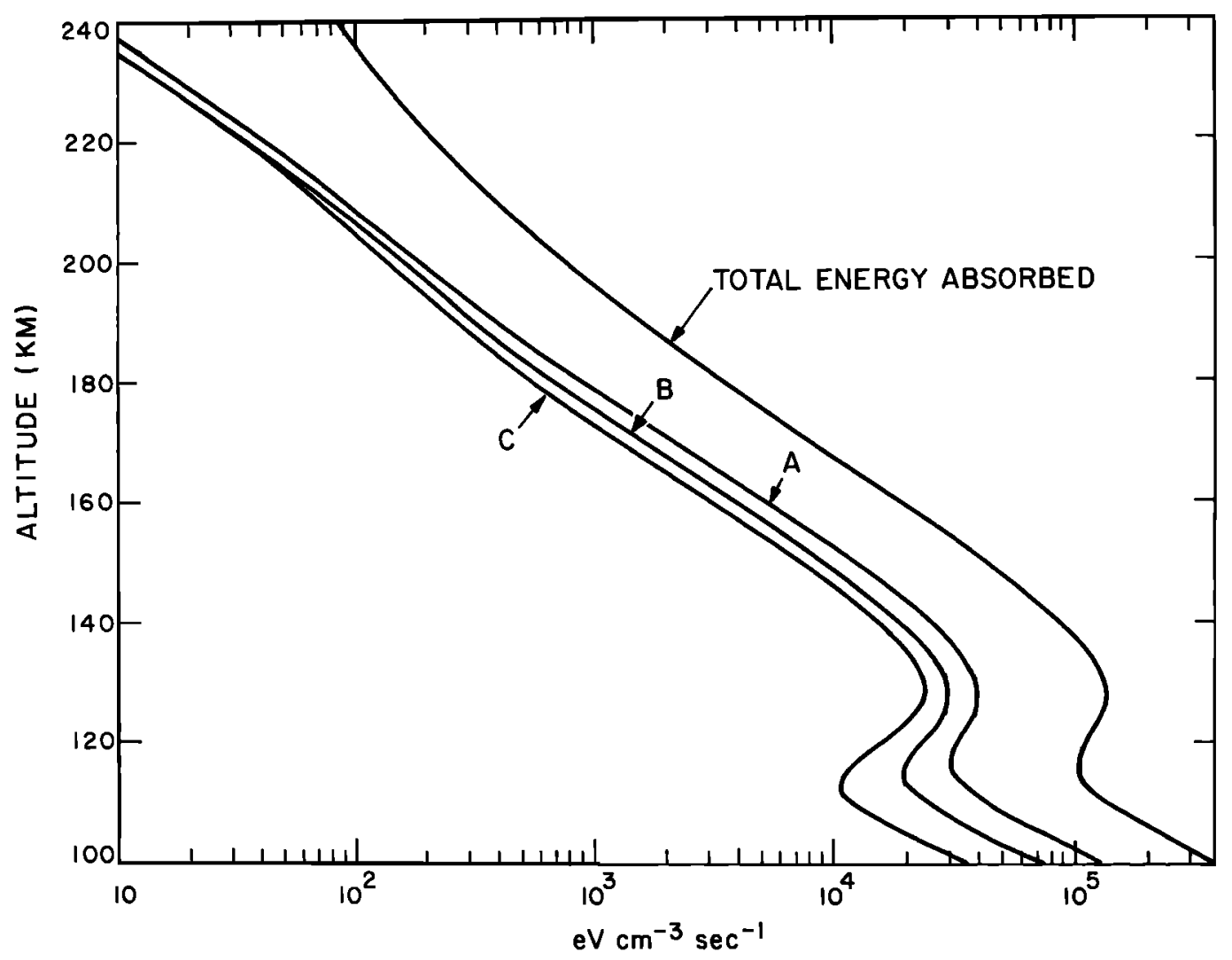

Fig. 14. Total rate of energy absorption and total heating rates for models A, B, and C.

tained by a simple extension of the dayglow and ionospheric calculations described earlier.

Figure 14 shows the total rate of energy absorption as a function of altitude. There are distinct peaks, one at $130 \mathrm{~km}$ due to ionizing radiation and the other, not shown, at $90 \mathrm{~km}$ due to dissociating radiation. Figure 14 also shows the heat energy deposition for the three models A, B, and C. Models B and $C$ merge at high altitudes where $O\left({ }^{1} D\right)$ is deactivated by emission of the $6300-\AA$ red line.

At an altitude of $130 \mathrm{~km}$ on Mars, the maximum heating rate is $3.2 \times 10^{-8} \mathrm{erg} \mathrm{cm}^{-3} \mathrm{~s}^{-1}$, and at $88 \mathrm{~km}$ it is $1 \times 10^{-6} \mathrm{erg}$ $\mathrm{cm}^{-3} \mathrm{~s}^{-1}$. The comparable rates in the terrestrial atmosphere are between 3 and $25 \times 10^{-8} \mathrm{erg} \mathrm{cm}^{-3} \mathrm{~s}^{-1}$ at $125 \mathrm{~km}$ and $3 \times$ $10^{-6} \mathrm{erg} \mathrm{cm}^{-3} \mathrm{~s}^{-1}$ at $100 \mathrm{~km}$ [Izakov and Morozov, 1970].

The heating efficiencies corresponding to the three models are shown in Figure 15 . Between 120 and $210 \mathrm{~km}, \epsilon$ varies slowly with altitude with values close to $0.27,0.20$, and 0.16 for models A, B, and C, respectively. Below $120 \mathrm{~km}$, dissociation becomes a larger heat source than ionization, and at $100 \mathrm{~km}, \epsilon$ moves to new values of $0.32,0.18$, and 0.08 for models $A, B$, and $C$, respectively. A value in the neighborhood of 0.1 will be achieved if photodissociation and quenching of $O\left({ }^{1} D\right)$ atoms lead to vibrationally excited molecules.

Above an altitude of $200 \mathrm{~km}$ the solar radiation is absorbed mainly by atomic oxygen. The $\mathrm{O}^{+}$ions produced diffuse downward and deposit their energy at lower altitudes. The heating profile is dominated by dissociative recombination of $\mathrm{O}_{2}{ }^{+}$, and the heating efficiencies decrease with increasing altitude toward values of less than 0.1 .

Our discussion ignores the heating contributions from reactions of the metastable $\mathrm{O}^{+}\left({ }^{2} D\right)$ state, which is produced in about one third of the photo-ionizations of atomic oxygen.
The radiative lifetime of the ${ }^{2} D_{3 / 2}$ state is $5 \times 10^{3} \mathrm{~s}$ and of the ${ }^{2} D_{5 / 2}$ state $2 \times 10^{4} \mathrm{~s}$ [Seaton and Osterbrock, 1957]. Deactivation by electron impact proceeds with a rate coefficient of about $7.8 \times 10^{-8}\left(T_{e} / 300\right)^{1 / 2} \mathrm{~cm}^{3} \mathrm{~s}^{-1}$ [Henry et al., 1969], by reaction with $\mathrm{N}_{2}$ with a rate coefficient of about $1.6 \times 10^{-10} \mathrm{~cm}^{3}$

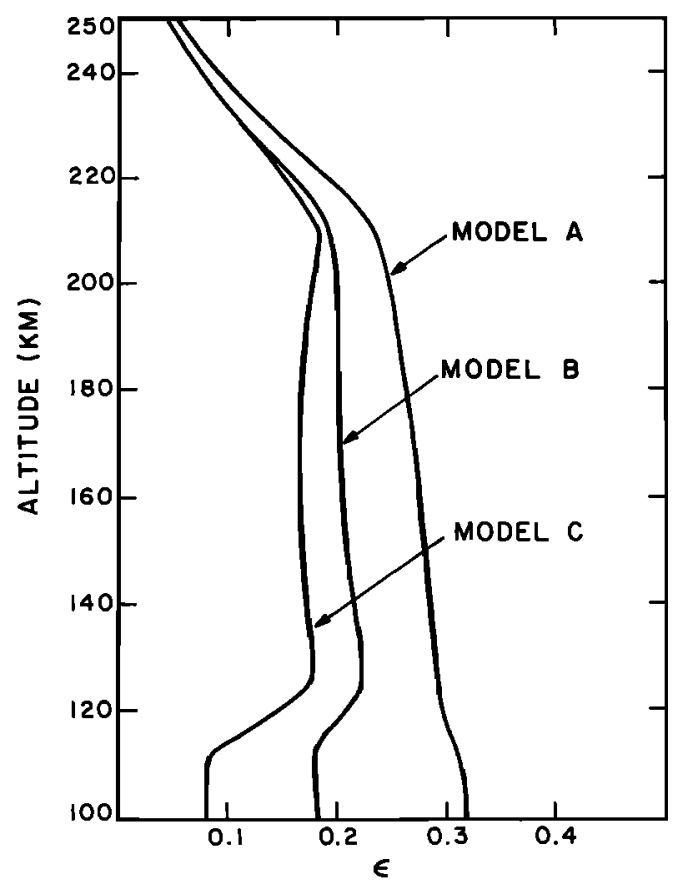

Fig. 15. Heating efficiency $\epsilon$ averaged over the wavelength range 14$2000 \AA$ for models A, B, and C. 


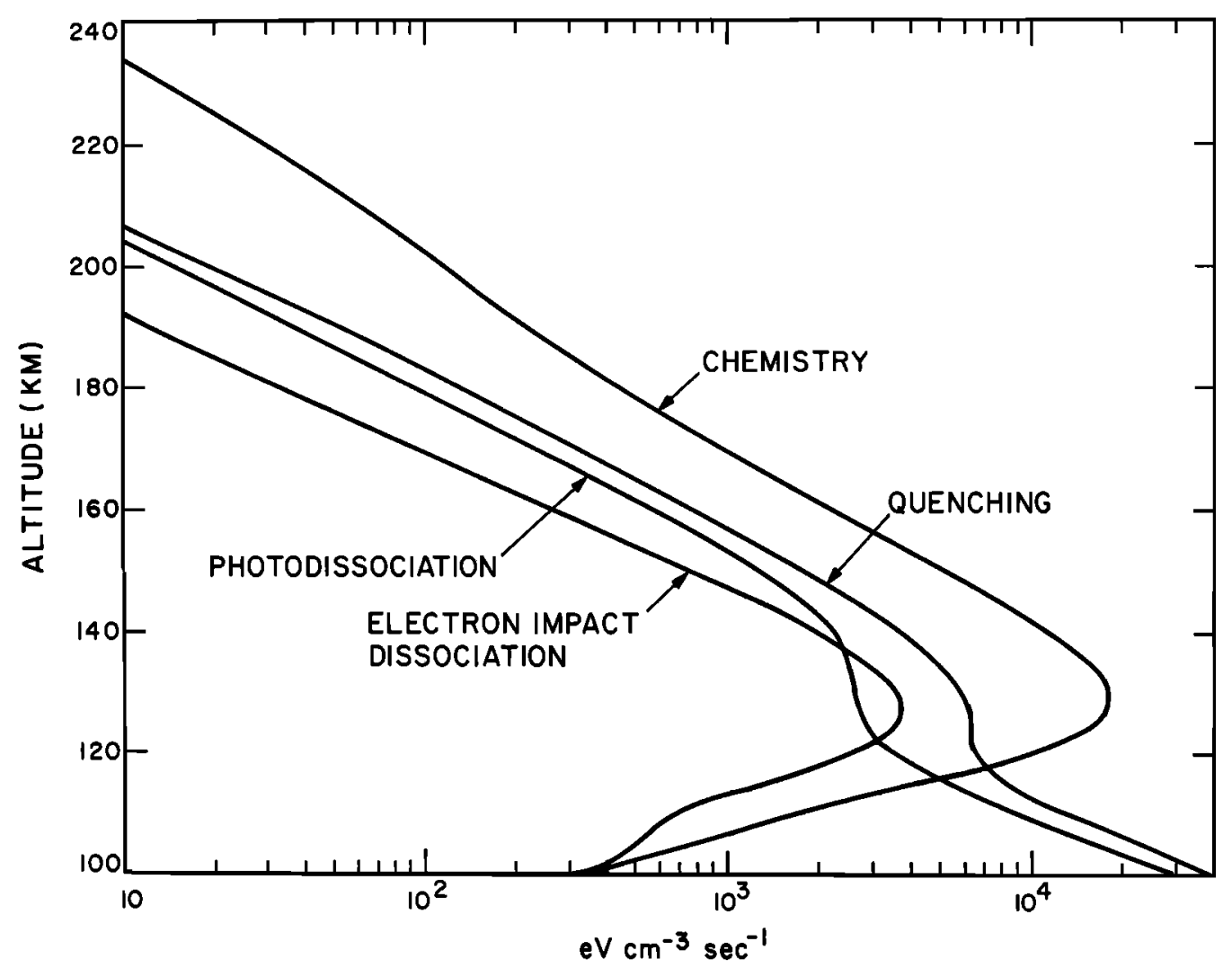

Fig. 16. The sources of neutral heating for model B. The curve labeled chemistry includes dissociative recombination and charge transfer reactions.

$\mathrm{s}^{-1}$ [Glosik et al., 1978], and by reaction with $\mathrm{O}$ with a rate coefficient much less than $3 \times 10^{-11} \mathrm{~cm}^{3} \mathrm{~s}^{-1}$ [Torr and Orsini, 1978]. Measurements have been made at ion energies above $0.5 \mathrm{eV}$ of the charge transfer of $\mathrm{O}^{+}\left({ }^{2} D\right)$ with $\mathrm{CO}_{2}$ [Moran and Wilcox, 1978], but the thermal rate coefficients of the reactions of $\mathrm{O}^{+}\left({ }^{2} D\right)$ with $\mathrm{CO}_{2}$ are unknown. If, as seems probable, reaction is rapid, the heating at $220 \mathrm{~km}$ is enhanced by about
$20 \mathrm{eV} \mathrm{cm}^{-3} \mathrm{~s}^{-1}$, and the heating efficiency is increased by 0.1 Thus the decrease of $\epsilon$ with altitude above $210 \mathrm{~km}$, suggested in Figure 15, may not occur. The metastable ions may have important effects on the ion temperature.

Figure 16 shows the altitude profiles of the neutral particle heat sources corresponding to the intermediate model $\mathrm{B}$. The curve labeled chemistry is the sum of the heating from ion-

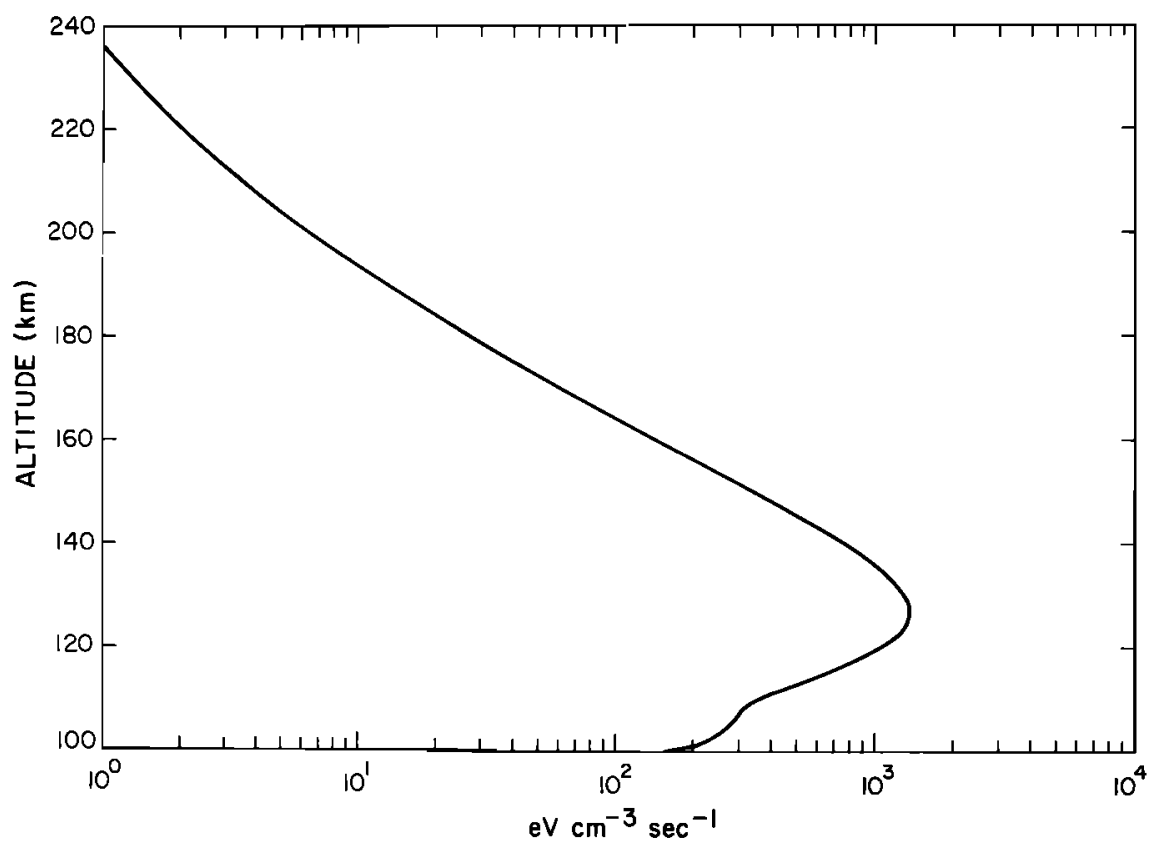

Fig. 17. The altitude profile of the heat deposited as kinetic energy of ions. 
molecule reactions and dissociative recombination. Dissociative recombination of $\mathrm{O}_{2}{ }^{+}$accounts for $70 \%$ of the heat deposited above the ionosphere peak at $130 \mathrm{~km}$.

Below $120 \mathrm{~km}$, photodissociation of $\mathrm{CO}_{2}$ and the quenching of metastable atoms produced by photodissociation of $\mathrm{CO}_{2}$ are the major heat sources. At $130 \mathrm{~km}$ a large source is provided by the quenching of $O\left({ }^{\prime} D\right)$ atoms produced by dissociative recombination.

At altitudes near $100 \mathrm{~km}$ our results for heating by photodissociation are similar to those of Dembovskii et al. [1976].

The presence of atomic oxygen in the Martian atmosphere increases the heating efficiency [Stewart, 1972]. In its absence, $\mathrm{CO}_{2}{ }^{+}$would be the major ion, and much of the energy liberated by dissociative recombination would appear as emission in the Cameron bands and would not be available as thermal energy.

The heat sources shown in Figure 16 exclude the kinetic energies carried by the ionic reaction products. The energies are lost by collisions with the neutral and ionized components of the atmosphere, and the resulting heat source raises the ion temperature above the neutral temperature [Rohrbaugh et al., 1979]. In Figure 17 we present the altitude profile of the heat deposited as kinetic energy, calculated by assuming that half the available energy is lost to vibrational excitation. Our values are somewhat larger than those calculated by Rohrbaugh et al. [1979].

From a comparison with Viking data on ion temperatures, Rohrbaugh et al. [1979] concluded that their calculated heat source is too small at high altitudes. The discrepancy is less with our heat source but is still significant. Neither of the calculated heat sources includes any contribution from reactions of $\mathrm{O}^{+}\left({ }^{2} D\right)$ ions. No laboratory data exist at thermal energies. If $\mathrm{O}^{+}\left({ }^{2} D\right)$ reacts rapidly with $\mathrm{CO}_{2}$ to produce energetic $\mathrm{O}_{2}^{+}$ ions, it would provide a large additional ion heat source at high altitudes.

Acknowledgments. This research was supported in part by the Aeronomy Program, Division of Atmospheric Sciences, National Science Foundation.

The Editor thanks T. E. Cravens and A. I. Stewart for their assistance in evaluating this paper.

\section{REFERENCES}

Ajello, J. M., Emission cross sections of $\mathrm{CO}$ by electron impact in the interval 1260-5000 A, 1, J. Chem. Phys., 55, 3158-3168, 1971.

Anicich, V. G., W. T. Huntress, and J. H. Futrell, Ion cyclotron resonance studies of some reactions of $\mathrm{C}^{+}$ions, Chem. Phys. Lett., 40, 233-236, 1976.

Atkinson, R., and K. H. Welge, Temperature dependence of $O\left({ }^{\prime} S\right)$ deactivation by $\mathrm{CO}_{2}, \mathrm{O}_{2}, \mathrm{~N}_{2}$, and Ar, J. Chem. Phys., 57, 3689$3693,1972$.

Barth, C. A., W. G. Fastie, C. W. Hord, J. B. Pearce, K. K. Kelly, A. 1. Stewart, G. E. Thomas, G. P. Anderson, and O. F. Raper, Mariner 6: Uitraviolet spectrum of Mars upper atmosphere, Science, 165, 1004-1005, 1969.

Barth, C. A., C. W. Hord, J. B. Pearce, K. K. Kelly, G. P. Anderson, and A. I. Stewart, Mariner 6 and 7 ultraviolet spectrometer experiment, J. Geophys Res., 76, 2213-2227, 1971.

Barth, C. A., C. W. Hord, A. I. Stewart, and A. L. Lane, Mariner 9 ultraviolet spectrometer experiment: Initial results, Science, 175, 309-312, 1972.

Bates, D. R., Forbidden oxygen and nitrogen lines in the nightglow, Planet. Space Sci., 26, 897-912, 1978.

Benesch, W., J. T. Vanderslice, S. G. Tilford, and P. G. Wilkinson, Franck-Condon factors for observed transitions in $\mathrm{N}_{2}$ above $6 \mathrm{eV}$, Astrophys. J., 143, 236-252, 1966 .

Benesch, W., J. T. Vanderslice, S. G. Tilford, and P. G. Wilkinson, Franck-Condon factors for permitted transitions in $\mathrm{N}_{2}$, Astrophys. $J ., 144,408-418,1966 b$
Brinkman, R. T., Mars: Has nitrogen escaped?, Science, 174, 944-945, 1971.

Butler, D. M., and R. S. Stolarski, Photoelectrons and electron temperatures in the Venus ionosphere, J. Geophys. Res., 83, 2057-2065, 19/8.

Cairns, R. B., and J. A. R. Samson, Absorption and photo-ionization cross sections of $\mathrm{CO}_{2}, \mathrm{CO}, \mathrm{Ar}$, and $\mathrm{He}$ at intense solar emission lines, J. Geophys. Res., 70, 99-104, 1965.

Carter, V. I., High-resolution $\mathrm{N}_{2}$ absorption study from 730 to $980 \AA$ J. Chem. Phys., 36, 4195-4205, $19 / 2$.

Cartwright, C. D., S. Trajmar, A. Chutjian, and W. Williams, Electron impact excitation of the electronic states of $N_{2}$, II, Integral cross sections at incident energies from 10 to $50 \mathrm{eV}$, Phys. Rev. $A$, 16, 1041-1051, 1977.

Chen, R. H., T. E. Cravens, and A. F. Nagy, The Martian ionosphere in light of the Vikıng observations, J. Geophys. Res., 83, 3871-3876, 1978.

Chutjian, A., D. C. Cartwright, and S. Trajmar, Electron impact excitation of the electronic states of $\mathrm{N}_{2}$, III, Transitions in the 12.5$14.2 \mathrm{eV}$ energy loss region at incident energies of 40 and $60 \mathrm{eV}$, Phys. Rev. A, 16, 1052-1060, 1977.

Clark, D., and J. F. Noxon, Photodissociation of $\mathrm{CO}_{2}$ on Mars, J. Geophys. Res., 75, 7307-7310, 1970.

Clerc, $M$., and $\bar{F}$. Barat, Kinetics of $\mathbf{C O}$ formation studied by far-UV flash photolysis of $\mathrm{CO}_{2}, J$. Chem. Phys., 46, 107-110, 1967.

Cook, G. R., and P. H. Metzger, Photo-1onization and absorption cross sections of $\mathrm{O}_{2}$ and $\mathrm{N}_{2}$ in the 600-1000 $\AA$ region, J. Chem. Phys., 41, 321-336, 1964.

Covey, R., K. A. Saum, and W. Benesch, Transition probabilities for the $W^{3} \triangle_{u}-B^{3} \Pi_{g}$ system of molecular nitrogen, J. Opt. Soc. Amer., 63, 592-596, 1973.

Cravens, T. E., G. A. Victor, and A. Dalgarno, The absorption of energetic electrons by molecular hydrogen gas, Planet. Space Sci., 23, 1059-1070, 1975.

Dalgarno, A., and G. Lejeune, The absorption of electrons in atomic oxygen, Planet. Space Sci., 19, 1653-1667, 1911.

Dalgarno, A., and M. B. McElroy, Mars: Is nitrogen present?, Science, $170,167-168,1970$

Dalgarno, A., R. J. W. Henry, and A. L. Stewart, The photo-ionization of atomic oxygen, Planet. Space Sci., 12, 235-246, 1964.

Dembovskii, A. V., M. N. Izakov, and O. G. Lisin, Photodissociation of $\mathrm{CO}_{2}$ and the accompanying heat release and emission features in the thermospheres of Mars and Venus, Cosmic Res. USSR, 13, 77I$781,1976$.

DeMore, W. B., and M. Mosesman, Photolysis of $\mathrm{CO}_{2}$ at $1849 \AA$, J. Atmos. Sci., 28, 842-846, 1971.

Dibeler, V. H., and J. A. Walker, Mass spectrometric study of photoionization, V1, $\mathrm{O}_{2}, \mathrm{CO}_{2}, \mathrm{COS}$ and $\mathrm{CS}_{2}$, J. Opt. Soc. Amer., 57, 1007-1012, 1967.

Dickinson, R. E., and E. C. Ridley, Venus mesosophere and thermosphere temperature structure, II, Day-night variations, Icarus, 30 , 163-178, 1977.

Dreyer, J. W., D. Perner, and C. R. Roy, Rate constants for the quenching of $\mathrm{N}_{2}\left(A^{3} \Sigma_{u}{ }^{+}, v_{A}=0-8\right)$ by $\mathrm{CO}, \mathrm{CO}_{2}, \mathrm{NH}_{3}, \mathrm{NO}$ and $\mathrm{O}_{2}$, J. Chem. Phys., 61, 3164-3169, 1974.

Eland, J. H. D., Predissociation of triatomic ions studied by photoelectron-photoion coincidence spectroscopy and photoion kinetic energy analysis, $\mathrm{I}, \mathrm{CO}_{2}{ }^{+}$, Int. J. Mass. Spectrom. Ion Phys., 9, 397412, 1972.

Eland, J. H. D., and J. Berkowitz, Formation and predissociation of $\mathrm{CO}_{2}{ }^{+}\left(C^{2} \Sigma_{g}{ }^{+}\right)$, J. Chem. Phys., 67, 2782-2787, 1977.

Fensenfeld, $\vec{F}$. C., A. L. Schmeitekopf, and E. E. Ferguson, Thermal energy ion-neutral reaction rates, $V$, Measured rate constants for $\mathrm{C}^{+}$and $\mathrm{CO}^{+}$reactions with $\mathrm{O}_{2}$ and $\mathrm{CO}_{2}, J$. Chem. Phys., 45, 23-25, 1966.

Fehsenfeld, F. C., D. B. Dunkin, and E. E. Ferguson, Rate constants for the reaction of $\mathrm{CO}_{2}{ }^{+}$with $\mathrm{O}, \mathrm{O}_{2}$ and $\mathrm{NO} ; \mathrm{N}_{2}{ }^{+}$with $\mathrm{O}$ and $\mathrm{NO}$; and $\mathrm{O}_{2}{ }^{+}$with NO, Planet. Space Sci., 18, 1267-1269, 1970.

Fox, J., and A. Dalgarno, Electron energy deposition in carbon dioxide, Planet. Space Sci., 29, 491-502, 1979.

Fox, J., A. Dalgarno, E. R. Constantinides, and G. A. Victor, The nitrogen dayglow on Mars, J. Geophys. Res., 82, 1615-1616, $1977 a$.

Fox, J., A. Dalgarno, and G. A. Victor, The absorption of energetic electrons by argon gas, Planet. Space Sci, 25, 71-78, 1977 b.

Fryar, J., and R. Browning, Molecular photo-ionization at $584 \AA$ and 304 A, Planet. Space Sci., 21, 709-711, 1973.

Gentieu, E. P., and J. E. Mentall, Cross sections for production of the 
$\operatorname{CO}\left(A^{1} \Pi-X^{1} \Sigma\right)$ fourth positive band system and $O\left({ }^{3} S\right)$ by photodissociation of $\mathrm{CO}_{2}, \mathrm{~J}$. Chem. Phys., 58, 4803-4815, 1973.

Glosik, J., A. B. Rakshit, N. D. Twiddy, N. G. Adams, and D. Smith, Measurement of the rates of ground and metastable excited states of $\mathrm{O}_{2}{ }^{+}, \mathrm{NO}^{+}$, and $\mathrm{O}^{+}$with atmosphere gases at thermal energy, J. Phys. B, $11,3365-3380,1978$.

Green, A. E. S., and C. A. Barth, Calculations of ultraviolet molecular nitrogen emissions from the aurora, J. Geophys. Res., 70, 10831092,1963 .

Gustafison, T., E. W. Plummer, D. E. Eastman, and W. Gudat, Partial photo-ionization cross sections of $\mathrm{CO}_{2}$ between 20 and $40 \mathrm{eV}$ studied with synchrotron radiation, $\bar{P}$ hys. $\bar{K}$ ev. $A, \overline{1} \overline{7}, 1 \overline{7}-1 \overline{8} 1,197 \overline{8}$.

Gutcheck, R. A., and E. C. Zipf, Excitation of the CO fourth positive system by the dissociative recombination of $\mathrm{CO}_{2}{ }^{+}$ions, J. Geophys. Res., 78, 5429-5436, 1973.

Hanson, W. B., S. Sanatani, and D. R. Zuccaro, The Martian ionosphere as observed by the Viking retarding potential analyzers, J. Geophys. Res., 82, 4351-4363, 1977 .

Hays, P. B., D. W. Rusch, R. G. Roble, and J. C. G. Walker, The O I (6300-A) airglow, Rev. Geophys. Space Phys., 10, 225-232, $197 \overline{8}$.

Heath, $\bar{D}$. F., and $\bar{M}$. $\overline{\mathbf{P}}$. Thekaekara, The solar spectrum between 1200 and $3000 \AA$, in The Solar Output and lts Variations, p. 193, Colorado Associated University Press, Boulder, Colo., 1977.

Heidner, R. F., and D. Husain, Quenching of $O\left({ }^{\prime} D_{2}\right)$ by atmospheric gases, Nature Phys. Sci., 241, 10-11, 1973.

Henry, $\bar{R}$. J. $\overline{\text { W., }}$ Photo-ionization cross sections for atomic oxygen, Planet. Space Sci., 15, 1747-1755, 1967.

Henry, R. J. W., and M. B. McElroy, Photoelectrons in planetary atmospheres, in The Atmospheres of Mars and Venus, edited by J. C. Brandt and M. B. McElroy, Gordon and Breach, New York, 1968.

Henry, R. J. W., P. G. Burke, and A. V. Sinfailam, Scattering of electrons by $\mathrm{C}, \mathrm{N}, \mathrm{O}, \mathrm{N}^{+}, \mathrm{O}^{+}, \mathrm{O}^{++}$, Phys. Rev., $178,218,1969$.

Hinteregger, H. E., EUV fluxes in the solar spectrum below $2000 \AA, J$. Atmos. Terr. Pिhys., $\overline{3} \overline{8}, \overline{7} \bar{y} 1-\overline{8} \overline{6}$, $19 \overline{9} \overline{6}$.

Huffman, R. E., Absorption cross sections of atmospheric gases for use in aeronomy, Can. J. Chem., 47, 1823-1834, 1969.

Hughes, B. M., and T. O. Tiernan, Determination of the abundance of excited $\mathrm{O}^{\top}$ ions in beams produced by electron impact on $\mathrm{O}_{2}$, $\mathrm{CO}_{2}, \mathrm{~N}_{2} \mathrm{O}, \mathrm{NO}_{2}$, and $\mathrm{H}_{2} \mathrm{O}$, J. Chem. Phys., 55, 3419-3426, 1971.

Huntress, W. T., Laboratory studies of bimolecular reactions of positive ions in interstellar clouds, in comets, and in planetary atmospheres of reducing composition, Astrophys. J. Suppl. Ser., 33, 495514, 1977.

Inn, E. C. Y., CO quantum yield in the photolysis of $\mathrm{CO}_{2}$ at $\lambda 1470$ and $\lambda \lambda 1500-1670, J$. Geophys. Res., 77, 1991-1993, 1972.

Inn, E. C. Y., and J. M. Heimerl, The photolysis of $\mathrm{CO}_{2}$ at wavelengths exceeding $1740 \hat{A}, J$. Atmos. Sci., 28, 838-841, 1971.

Izakov, $\bar{M}$. N., and $\mathbf{S}$. $\bar{K}$. Morozov, Heating function of the thermosphere, II, Heating of the thermosphere by solar radiation in the Schumann-Runge continuum, Geomagn. Aeron., 10, 4995-4999, $19 \overline{7} 0$.

Johnson, R. E., Comment on ion and electron temperatures in the Martian upper atmosphere, Geophys. Res. Lett., 5, 989-992, 1978.

Judge, D. L., and L. C. Lee, Cross sections for the production of $\operatorname{CO}\left(a^{3} \Sigma^{+}, d^{\beta} \triangle_{l}\right.$, and $\left.e^{3} \Sigma^{-} \rightarrow a^{3} \Pi\right)$ fluorescence through photodissociation of $\mathrm{CO}_{2}$, J. Chem. Phys., 58, 104-107, 1973.

Krasnopolsky, V. A., On the structure of Mars atmosphere at 120-220 km, Icarus, 24, 28-35, 1975.

Kurt, V. G., A. S. Smirnov, L. G. Titarchuk, and S. D. Chuvahin, Observations of $\mathrm{OI} 1300-\hat{A}$ radiation in the Martian atmosphere, Icarus, 21, 35-41, 1974.

Laudenslager, J. B., W. T. Huntress, and M. T. Bowers, Near-thermal energy charge transfer reactions of rare gas ions with diatomic and simple polyatomic molecules: The importance of Franck-Condon factors and energy resonances on the magnitude of the reaction rate constants, J. Chem. Phys., 61, 4600-4617, 1974.

Lawrence, G. M., Photodissociation of $\mathrm{CO}_{2}$ to produce $\mathrm{CO}\left(a^{3} \Pi\right), J$. Chem. Phys., 56, 3435-3442, $1972 a$.

Lawrence, G. M., Production of $O\left({ }^{1} S\right)$ from photodissociation of $\mathrm{CO}_{2}$, J. Chem. Phys., 57, 5616-5617, $1972 b$.

Leach, S., M. Devoret, and J. H. D. Eland, Fluorescence quantum yields of isotopic $\mathrm{CO}_{2}{ }^{+}$ions, Chem. Phys., 33, 113-121, 1978 a.

Leach, S., P. R. Stannard, and W. M. Gelbart, Interelectronic-state perturbation effects on photoelectron spectra and emission quantum yields: Application to $\mathrm{CO}_{2}^{+}$, Mol. Phys., 36, 1119-1132, 19786 .

Lee, L. C., and $D$. L. Judge, Cross sections tor the production of $\mathrm{CO}_{2}{ }^{+}\left[A^{2} \Pi_{u}, B^{2} \Sigma_{u}{ }^{+} \rightarrow X^{2} \Pi_{g}\right]$ fluorescence by vacuum ultraviolet radiation, J. Chem. Pinys., $57,4443-4445,1972$.
Lee, L. C., R. W. Carlson, D. L. Judge, and M. Ogawa, The absorp tion cross sections of $\mathrm{N}_{2}, \mathrm{O}_{2}, \mathrm{CO}, \mathrm{NO}, \mathrm{CO}_{2}, \mathrm{~N}_{2} \mathrm{O}, \mathrm{CH}_{4}, \mathrm{C}_{2} \mathrm{H}_{6}$, anc $\mathrm{C}_{4} \mathrm{H}_{10}$ from 180 to $700 \AA$, J. Quant. Spectrosc. Radiat. Transfer, 13 1023-1031, 1973.

Lee, L. C., R. W. Carlson, D. L. Judge, and M. Ogawa, Vacuum ul. traviolet fluorescence from photodissociation fragments of $\mathrm{CO}$ anc $\mathrm{CO}_{2}$, J. Chem. P̈hys., 63, 3987-3995, 1975.

Lindinger, W., D. L. Albritton, F. C. Fehsenfeld, and E. E. Ferguson Laboratory measurements of the ionospheric $\mathrm{O}_{2}{ }^{+}\left(X^{2} \Pi_{\mathrm{g}}\right)$ anc $\mathrm{O}_{2}{ }^{+}\left(a^{4} \Pi_{u}\right)$ reactions with NO, J. Geophys. Res., 80, 3725-3726 1975.

Mahan, B. H., Photolysis of carbon dioxide, J. Chem. Phys., 33, 959965, 1960.

Mantas, G. P., and W. P. Hanson, Photoelectron fluxes in the Martiar atmosphere, J. Geophys. Res., 84, 369-386, 1979.

McCallum, J. C., and R. W. Nicholls, Relative intensity measure. ments in the Fox-Duffendack-Barker $\left(A^{2} \Pi_{w}-X^{2} \Pi_{g}\right)$ and the ul. traviolet doublet $\left(B^{2} \Sigma_{u}{ }^{+}-X^{2} \Pi_{g}\right)$ band systems of $\mathrm{CO}_{2}{ }^{+}, J$. Phys. $B$ 5, 1417-1426, 1972.

McConnell, J. C., The atmosphere of Mars, in Physics and Chemistr) of Upper Atmospheres, edited by B. M. McCormac, pp. 309-334, D Reidel, Hingham, Mass., 1973.

McConnell, J. C., The ionospheres of Mars and Venus, Ann. Rev. Earth Planet. Sci., 4, 319-346, 1976.

McConnell, J. C., and M. B. McElroy, Excitation processes for Mar. tian dayglow, J. Geophys. Res., 75, 7290-7293, 1970.

McCulioh, K. E., Photo-ionization of carbon dioxide, J. Chem. Phys. $59,4250-4259,1973$.

McElroy, M. B., Mars: An evolving atmosphere, Science, 175, 443445, 1972.

McElroy, M. B., Atomic and molecular processes in the Martian atmosphere, Advan. At. Mol. Phys., 9, 323-363, 1973.

McElroy, M. B., and J. C. McConnell, Atomic carbon in the atmospheres of Mars and Venus, J. Geophys. Res., 76, 6674-6689, 1971.

McElroy, M. B., T. Y. Kong, Y. L. Yung, and A. O. Nier, Composition and structure of the Martian atmosphere: Analysis and results from Viking, Science, 194, 1295-1298, 1976.

McFarland, M., D. L. Albritton, F. C. Fehsenfled, E. E. Ferguson. and $A$. L. Schmeitekopf, Energy dependence and branching ratios of the $\mathrm{N}_{2}{ }^{-}+O$ reaction, J. Geophys. Res., 79, 2925-2926, 1974.

McGuire, E. J., Photo-ionization cross sections of the elements helium to xenon, Phys. Rev. A, 175, 20-30, 1968.

Moran, T. F., and J. B. Wilcox, Charge transfer reactions of ground state $\hat{O}^{+}\left({ }^{4} S\right)$ and $\hat{O}^{+}\left({ }^{2} D\right)$ state ions with neutral molecules, J. Chem. Phys., 69, 1397-1405, 1978.

Mul, P. M., and J. W. McGowan, Temperature dependence of dissociative recombination for atmospheric ions $\mathrm{NO}^{+}, \mathrm{O}_{2}{ }^{+}, \mathrm{N}_{2}{ }^{+}, J$. Phys. B, 12, 1591-1602, 1979.

Mumma, M. J., E. J. Stone, and E. C. Zipf, Excitation of the CO fourth positive band system by electron impact on carbon dioxide, J. Chem. Phys., 54, 2627-2634, 1971.

Nakata, R. S., K. Watanabe, and F. M. Matsunaga, Absorption and photo-ionization coefficients of $\mathrm{CO}_{2}$ in the region $580-1970 \mathrm{~A}, \mathrm{Sci}$. Light, J4, 54-71, 1965.

Niehaus, A., Anregung und Dissoziation von Molekülen beim Elektronenbeschuss, $Z$. Naturforsch. A, 22, 690-708, 1967.

Nier, A. O., and M. B. McElroy, Structure of the neutral upper atmosphere of Mars: Results from Viking 1 and Viking 2, Science, 194, $1298-1300,1976$.

Nier, A. O., and M. B. McElroy, Composition and structure of Mars' upper atmosphere: Results from the neutral mass spectrometers on Viking 1 and 2, J. Geophys. Res., 82, 4341-4350, 1977.

Ogawa, M., Absorption cross sections of $\mathrm{O}_{2}$ and $\mathrm{CO}_{2}$ continua in the Schumann and far-UV regions, J. Chem. Phys., 54, 2550-2556, 1971.

Parr, G. R., and J. W. Taylor, Photo-ionization mass spectrometry, V, Carbon dioxide, Int. J. Mass Spectrom. Ion Phys., 14, 467-477, 1974.

Pierce, A. K., and R. G. Allen, The solar spectrum between 0.3 and 10 $\mu \mathrm{m}$, in The Solar Output and Its Variation, pp. 169-192, Colorado Associated University Press, Boulder, Colo., 1977.

Rapp, D., and P. Englander-Golden, Total cross sections for ionization and attachment in gases by electron impact, I, Positive ionization, J. Chem. Phys., 43, 1464-1478, 1965.

Rohrbaugh, R., P. J. S. Nisbet, E. Bleuler, and J. R. Herman, The effect of energetically produced $\mathrm{O}_{2}{ }^{+}$on the ion temperatures of the Martian thermosphere, J. Geophys. Res., 84, 3327-3338, 1979. 
Samson, J. A. R., The measurement of the photo-ionization cross sections of the atomic gases, Advan. At. Mol. Phys., 2, 177-261, 1966.

Samson, J. A. R., and J. L. Gardner, Fluorescence excitation and pho-

toelectron spectra of $\mathrm{CO}_{2}$ induced by vacuum uitravioiet radiation between 185 and 716 A, J. Geophys. Res., 78, 3663-3667, 1973a.

Samson, J. A. R., and J. L. Gardner, Fiuorescent cross sections and yields of $\mathrm{CO}_{2}{ }^{+}$from threshold to $185 \hat{A}, J$. Chem. Phys., 58, 3771$3774,1973 b$.

Samson, J. A. R., G. N. Haddad, and J. L. Gardner, Total and partial photo-ionization cross sections of $N_{2}$ from threshold to $100 \bar{A}, J$. Phys. B, 10, 1749-1758, 1977.

Schlag, E. W., R. Frey, B. Gotchev, W. B. Peatman, and H. Pollak,

Radiative lifetimes of ions from electron-photon coincidence measurements, Chem. Phys. Lelt., J1, 406-408, 1911.

Seaton, M. J., and $D$. Osterbrock, Kelative $U 11$ intensities in gaseous nebulae, Astrophys. J., 125, 66-81, 1957.

Shemansky, D. E., and A. L. Broadfoot, Excitation of $\mathbf{N}_{2}$ and $\mathbf{N}_{2}{ }^{+}$ systems by electrons, I, Absolute transition probabilities, J. Quant. Spectrosc. Rad. Transfer, $11,1385-1400,1971$.

Slanger, $\mathrm{I}$. $\mathrm{G}$., and $\mathrm{G}$. Black, The $\mathrm{CO}_{2}$ photolysis problem, J. Chem. Phys., 54, 1889-1898, 1971 .

Slanger, $\bar{T}$. $G$., and $G$. Black, Electronic to vibrational energy transfer in the $O\left({ }^{\prime} D\right)-\mathrm{N}_{2}$ and $O\left({ }^{\prime} D\right)-C O$ systems, J. Chem. Phys., 60, 468$477,1974$.

Slanger, T. G., and G. Black, $O\left({ }^{\prime} S\right)$ quenching by $O\left({ }^{3} P\right)$, J. Chem. Phys., 64, 3763-3766, 1976.

Slanger, T. G., and G. Black, $\mathrm{CO}_{2}$ photolysis revisited, J. Chem. Phys., 68, 1844-1849, 1978.

Slanger, T. G., R. L. Sharpless, and G. Black, $\mathrm{CO}_{2}$ photodissociation, 1060-1175 A, J. Chem. Phys., 67, 5317-5323, 1977.

Smith, D., N. G. Adams, and T. M. Miller, A laboratory study of the reactions of $\mathrm{N}^{+}, \mathrm{N}_{2}^{+}, \mathrm{N}_{3}^{+}, \mathrm{N}_{4}^{+}, \mathrm{O}^{+}, \mathrm{O}_{2}^{+}$, and $\mathrm{NO}^{+}$ions with several molecules at $300 \mathrm{~K}, J$. Chem. Phys., 69, 308-318, 1978.

Stewart, A. 1., Marner 6 and 7 ultraviolet spectrometer experiment: Implications of $\mathrm{CO}_{2}{ }^{+}, \mathrm{CO}$, and $\mathrm{U}$ airglow, J. Geophys. Kes., 77, 54 $68,1972$.

Stewart, R. W., and J. S. Hogan, Empirical determinations of heating efficiencies in the Mars and Venus atmospheres, J. Atmos. Sci., 26, 330-332, 1969.

Stewart, A. I., C. A. Barth, C. W. Hord, and A. L. Lane, Mariner 9 ultraviolet spectrometer experiment: Structure of Mars' upper atmosphere, Icarus, 17, 469-474, $19 \overline{7} 2$.

Stone, E. J., and E. C. Zipt, Electron impact excitation of the ${ }^{3} S^{\circ}$ and 'S' states of atomic oxygen, J. Chem. Phys., 60, 4237-4243, 1974.

Streit, G. E., C. J. Howard, A. L. Schmeltekopt, J. A. Davidson, and $H$. I. Schiff, Temperature dependence of $O\left({ }^{i} D\right)$ rate constants for reactions with $\mathrm{O}_{2}, \mathrm{~N}_{2}, \mathrm{CO}_{2}, \mathrm{O}_{3}$, and $\mathrm{H}_{2} \mathrm{O}$, J. Chem. Phys., 65, 47614764, 1976 .

Strickland, D. J., G. E. Thomas, and P. R. Sparks, Mariner 6 and 7 Uitraviolet spectrometer experiment: Analysis of the U 1 1304- and 1350-Å emissions, J. Geophys. Res., 77, 4052-4068, 1972.

Strickiand, D. J., A. I. Stewart, C. A. Barth, C. W. Hord, and A. L. Lane, Mariner 9 ultraviolet spectrometer experiment: Mars atomic oxygen 1304-A emission, J. Geophys. Res., 78, 4547-4559, 1973.

Taylor, $\bar{K}$. $\bar{T}$., and $\bar{P}$. $\bar{G}$. Burke, Photo-ionization of ground state carbon and oxygen atoms, J. Phys. B, 9, L353-L358, 1976.

Thomas, G. E., Neutral composition of the upper atmosphere of Mars as determined from the Mariner $\bar{U} \mathbf{V}$ spectrometer experiments, $J$. Atmos. Sci., $28,859-868,1971$.

Torr, D. G., and N. Orsini, The effect of $\mathrm{N}_{2}{ }^{+}$recombination on the aeronomic determination of the charge exchange rate coefficient of $\left.\overline{\mathrm{O}}^{+}{ }^{2} \bar{D}\right)$ with $\bar{N}_{2}$, Geophys. Kes. Lelt., $\bar{J}, 657-660$, $197 \overline{8}$.

van Brunt, J., F. W. Poweil, $\bar{K}$. G. Hirsch, and $\overline{\text { W. }} \overline{\text { D. Whitehead, }}$ Photo-ionization of $\mathrm{N}_{2}, \mathrm{O}_{2}, \mathrm{NO}, \mathrm{CO}$, and $\mathrm{CO}_{2}$ by soft $\mathrm{X}$ rays, $J$. Chem. Phys., 5\%, 31200-3129, 1972.

Wauchop, T. S., and H. P. Broida, Lifetime and quenching of $\mathrm{CO}\left(a^{3} \bar{I}\right)$ produced by recombination of $\mathrm{CO}_{2}$ ions in a helium atterglow, J. Chem. P̈hys., 56, 330-332, 1972.

Weller, C.S., and M. A. Biondi, Measurements of dissociative recombination of $\mathrm{CO}_{2}{ }^{+}$ions with electrons, Phys. Rev. Lett., 19, 59-61, 1967.

Wight, G. R., M. J. Van der Wiel, and C. E. Brion, Dipole excitation, ionization, and fragmentation of $N_{2}$ and $C O$ in the $10-60 \mathrm{eV}$ region, J. Phys. 3, 9, 675-689, 1976.

Winters, H. F., lonic absorption and dissociation cross sections for nitrogen, J. Chem. Phys., 44, 1472-1476, 1966.

Wu, C. Y., E. Phillips, L. C. Lee, and D. L. Judge, Atomic carbon emission from photodissociation of $\mathrm{CO}_{2}$, J. Geophys. Res., 83, 4869$4872,1978$.

Yung, Y. L., D. F. Strobel, T. Y. Kong, and M. B. McElroy, Photochemistry of nitrogen in the Martian atmosphere, Icarus, 30, 2641, $197 \overline{7}$.

Zipf, E. C., The dissociative recombination of $\mathrm{O}_{2}^{+}$ions into specifically identified final atomic states, Bull. Amer. Phys. Soc., 15, 498, 1970.

Zipf, E. C., and R. W. McLaughlin, On the dissociation of nitrogen by electron impact and by $\bar{E} \bar{U} \bar{V}$ photoabsorption, Planet. Space Sci., 26, 449-462, 1978 .

(Received March 20, 1979; revised July 24, 1979; accepted July 25, 1979.) 